\title{
ENVIRONMENTAL MONITORING REPORT FOR PANTEX PLANT COVERING 1977
}

Ronald E. Alexander

C. Newlyn Horton

Mason \& Hanger - Silas Mason Co., Inc.

Pantex Plant

P. 0. Box 30020

Amarillo, Texas 79177

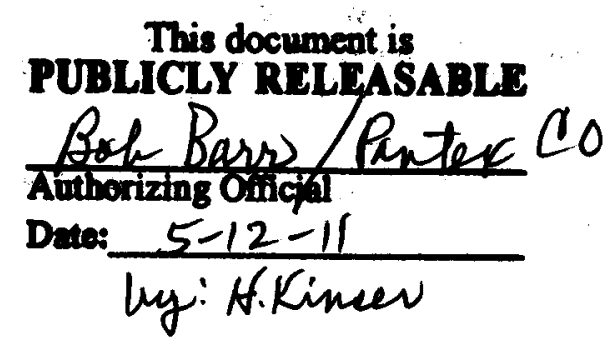

Operated for the DOE

Under U. S. Government

Contract EY-76-C-04-0487

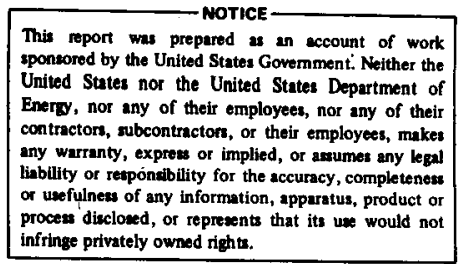




\section{DISCLAIMER}

This report was prepared as an account of work sponsored by an agency of the United States Government. Neither the United States Government nor any agency Thereof, nor any of their employees, makes any warranty, express or implied, or assumes any legal liability or responsibility for the accuracy, completeness, or usefulness of any information, apparatus, product, or process disclosed, or represents that its use would not infringe privately owned rights. Reference herein to any specific commercial product, process, or service by trade name, trademark, manufacturer, or otherwise does not necessarily constitute or imply its endorsement, recommendation, or favoring by the United States Government or any agency thereof. The views and opinions of authors expressed herein do not necessarily state or reflect those of the United States Government or any agency thereof. 


\section{DISCLAIMER}

Portions of this document may be illegible in electronic image products. Images are produced from the best available original document. 


\section{FOREWORD}

This report is prepared for the United States Department of Energy by the Environmental Health Section of Mason \& Hanger Silas Mason Co., Inc. Data are obtained through the combined efforts of the Health Physics and Industrial Hygiene groups. In addition to the authors mentioned the following personnel made significant contributions to this report:

Nancy Altsman

Ray Bradley

Vicki Cornelius

Quinton Gi11

Gary Haynie
Jim Keagy

Tom Koger

Steve Kouba

John Richards 


\section{TABLE OF CONTENTS}

$\underline{\text { Page }}$

ABSTRACT $\ldots \ldots \ldots \ldots \ldots \ldots \ldots \ldots \ldots \ldots \ldots \ldots \ldots \ldots \ldots \ldots \ldots \ldots \ldots$

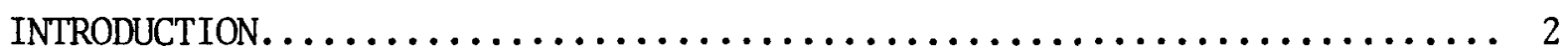

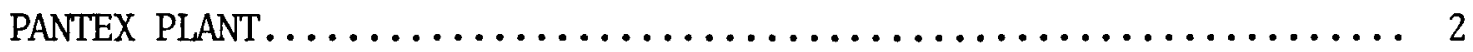

ENVIRONMENTAL SETTING......................... 3

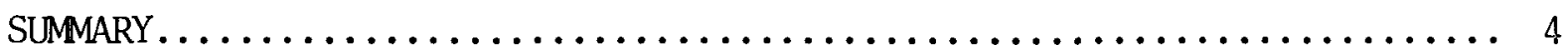

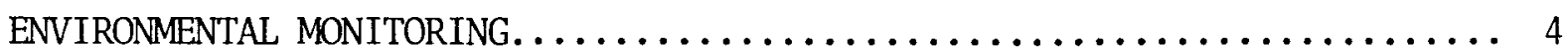

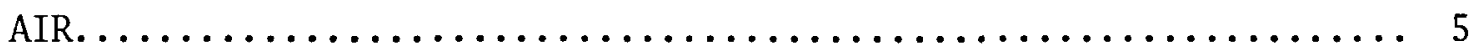

Radioactive.............................. 5

Non-Radioactive............................ 6

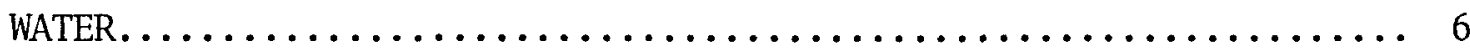

Radioactive.............................. 6

Non-Radioactive............................ 6

SOIL................................... 7

Radioactive.............................. 7

Non-Radioactive............................ 7

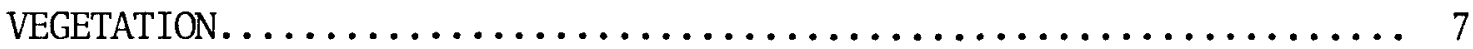

Radioactive.............................. 7

Non-Radioactive............................. 7

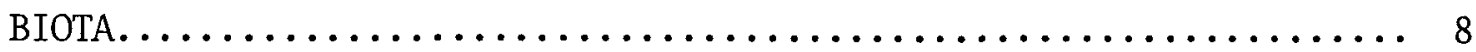

Radioactive............................... 8

Non-Radioactive............................ 8

CALCULATIONS OF POTENTIAL RADIATION DOSE TO THE PUBLIC

FROM PANTEX ACTIVITIES FOR $1977 \ldots \ldots \ldots \ldots \ldots \ldots \ldots \ldots \ldots \ldots \ldots \ldots \ldots$

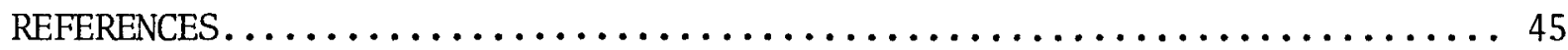

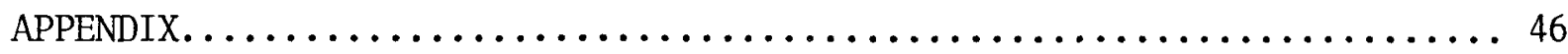

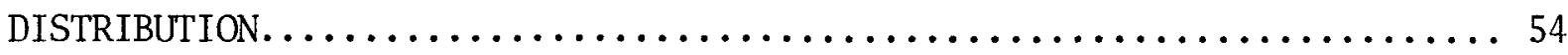




\section{LIST OF TABLES}

Number

$\underline{\text { Page }}$

I Estimated Atmospheric Releases of Radioactive

Material from Pantex for $1977 . . . \ldots \ldots \ldots \ldots \ldots \ldots . \ldots 17$

II Estimated Steam Generating Plant Emissions for

1977 .

III Population of Area Receptors Used in 1977 Uranium

and Tritium Calculations...................... 18

IV Calculated Uranium-in-Air and Tritium-in-Air

Contributions from Pantex Plant for $1977 \ldots \ldots \ldots \ldots \ldots 19$

V Pantex Vicinity Dose Calculation for $1977 \ldots \ldots \ldots \ldots \ldots 21$

VI Summary of Gross Alpha Activity in Air for 1977...... 22

VII Summary of Gross Beta Activity in Air for $1977 \ldots . . . .22$

VIII Summary of Uranium in Air for $1977 \ldots \ldots \ldots \ldots \ldots \ldots . . .23$

IX Summary of Plutonium-239 in Air for $1977 \ldots \ldots \ldots \ldots \ldots 24$

X Summary of Tritium Oxide in Air for $1977 \ldots \ldots \ldots \ldots 25$

XI Summary of Dissolved Alpha Activity in Water for 1977.. 26

XII Summary of Suspended Alpha Activity in Water for 1977.. 26

XIII Summary of Dissolved Beta Activity in Water for 1977... 27

XIV Summary of Suspended Beta Activity in Water for 1977... 27

XV Summary of Total Uranium in Water for $1977 \ldots \ldots \ldots \ldots 28$

XVI Summary of Plutonium-239 in Water for $1977 \ldots \ldots \ldots \ldots .29$

XVII Summary of Tritium Oxide in water for $1977 \ldots \ldots \ldots \ldots .29$

XVIII Summary of Total Uranium in Soil for $1977 \ldots \ldots \ldots \ldots . . .30$

XXIX Summary of Plutonium-239 in Soil for $1977 \ldots \ldots \ldots \ldots . \ldots 31$

XX Summary of Tritium Oxide in Soil for $1977 \ldots \ldots \ldots \ldots . \ldots 32$

XXI Summary of Total Uranium in Vegetation for $1977 \ldots \ldots \ldots 33$

XXII Summary of Tritium Oxide in Vegetation for $1977 \ldots \ldots . .34$

XXIII , Tota1 Uranium in Jackrabbit for $1977 \ldots \ldots \ldots \ldots \ldots \ldots \ldots$

XXIV Plutonium-239 in Jackrabbit for $1977 \ldots \ldots \ldots \ldots \ldots \ldots . \ldots$ 


\section{TABLES (Cont'd)}

Number

$\underline{\text { Page }}$

XXV Tritium in Jackrabbit for $1977 \ldots \ldots \ldots \ldots \ldots \ldots \ldots$

XXVI Organ Weights of Jackrabbit for $1977 \ldots \ldots \ldots \ldots \ldots \ldots$

XXVII Summary of Chemical Analyses for Water Pollution for

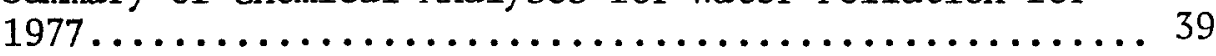




\section{LIST OF FIGURES}

Number

Page

$1 \quad$ Pantex Plant Vicinity Map................... 11

2 Pantex Plant Facility Map................... 12

3 Resultant Winds for Amari11o, Texas for $1977 \ldots . . . . . .13$

4 Pantex Environmental Air Sampling Network............ 14

$5 \quad$ Environmental Soil, Water and Vegetation Sampling

Locations for Pantex Plant.................... 15

6 Population within an 80 -Kilometer Radius of Pantex

Plant................................ 16 


\section{ABSTRACT}

During 1977 Pantex Plant conducted a monitoring program to determine the concentration of specific radioactive and non-radioactive species in the local environment.

Although the plant activities involve the handling of significant quantities of uranium, plutonium, and tritium, only small releases of uranium (depleted in the isotope ${ }^{235} U$ ) and tritium occurred which could have affected the local environment. Monitoring data indicate that concentrations of these nuclides in the environment are below established criteria for air and water and therefore should not present a health hazard either to employees or to the public. 


\section{INTRODUCTION}

\section{PANTEX PLANT}

Pantex Plant is operated by Mason $\xi$ Hanger - Silas Mason Co., Inc., as a prime contractor for the United States Department of Energy. Figs. 1 and 6 show the location in the Texas Panhandle.

Pantex Plant is located in Carson County Texas, 17 miles northeast of downtown Amarillo, Texas, on the north side of U.S. Highway 60 between the towns of Panhandle and Amari1lo. The plant site was established in 1951 on a 9100 acre portion of the former 14,950 acre Pantex Army Ordnance Plant which was constructed in 1942 for World War II conventional shel1 and bomb loading.

Actual Plant operations are performed within several zones (Ref. Figure 2). The remaining area is in native grasses and farmland, which is utilized for agricultural research purposes through an agreement between Texas Tech University and the USDOE.

The mission of Pantex Plant includes atomic weapons assembly, atomic weapons retirement, atomic weapons stockpile surveillance, fabrication of chemical high explosives, and testing of chemical high explosives. Weapons assembly and stockpile surveillance activities necessarily involve handling environmentally significant quantities of uranium, plutonium, and tritium, as well as non-radioactive potential pollutants.

Radioactive material releases at the Pantex site are restricted to certain infrequent high explosive test fires which disperse small quantities of depleted uranium (essentially 238U) and other operations within the plant which involve the release of tritium $\left({ }^{3} \mathrm{H}\right)$ in small amounts. Airborne discharges of radioactive material
(Table I) and steam generating plant emissions (Table II) are not treated but allowed to disperse into the atmosphere. In all cases emissions are well below prescribed standards and do not represent a hazard to personnel or the environment. All liquid discharges, including treated sanitary sewage, remain within the plant perimeter. There are no sources of continuous release of radioactive materials and a viable environmental monitoring program has been established to assure that no public health hazard exists. Operating buildings where weapons are assembled/disassembled are provided with continuously operating radiation sensors to detect any accidental release of radioactive materials which might occur.

With few exceptions, radioactive material is handled only in sealed containers which are not opened at Pantex, thus avoiding the possibility of releasing materials during normal operating conditions. In al1 cases every feasible effort is made to control radioactive materials releases to assure that concentrations are well within existing criteria for radioactivity in the environment.

Releases of radioactive and nonradioactive effluents are minimal. These releases do not represent a hazard to personnel or the environment. There are no liquid streams flowing through or from the plant facility and the Panhandle climate is characteristically windy. All 1iquid effluents are diverted to an on-site retention playa and utilized by Texas Tech University for crop irrigation within the plant perimeter. This water is principally condensate and sanitary sewage and is not a by-product of specific industrial processes. No radioactive or chemical high explosives are contained in effluents. 


\section{ENVIRONMENTAL SETTING}

Geologically, Pantex Plant is located in the Llano Estacado or Staked Plains. The vicinity is characterized by rolling grassy plains and numerous natural playas. These playas, frequently dry, are fed by rainwater and melted snow. Normal total precipitation is slightly less than 20 inches per year, but may vary from 10 to 40 inches per year. During 1977 the Amarillo office of the National Weather Service reported 19.18 inches of precipitation. The annual evaporation rate is equivalent to over 70 inches per year.

Local winds are predominantly from the south and southwest (Ref. Figure 3) and during 1977 had an average speed of 6.3 meters per second. The Texas Panhandle is an area of high tornado risk with central Oklahoma as the only other area in the United States experiencing a higher tornado frequency. The reported probability of the Pantex Plant being hit by a tornado during any given year is three chances in one thousand or $0.003(1)$.

The probability of experiencing earthquakes, however, is relatively low. The Uniform Building Code places the Pantex area in Zone 1 which rates second lowest in earthquake occurrence on a scale from zone 0 to Zone $3(2)$.

Underlying the Texas Panhandle is the Ogallala aquifer which serves as the primary source of water for Pantex and surrounding communities. Producing water wells on the Pantex Plant site are up to 244 metres deep although small quantities of usable water are available at about 76 metres. A surface layer of clay 18 to 24 metres deep forms a barrier to surface moisture and prevents deep percolation from surface contamination $(3,4,5)$. This clay layer is usually underlaid with caliche and dry Ogallala sands which cover the saturated aquifer. Aquifer water which is removed for use is only partially replaced through natural recharging processes.

The Panhandle area is not densely populated having approximately 236,000 persons residing within an 80 kilometer radius of the Pantex Plant (6). Amaril1o, Texas, located southwest of the plant site, is the largest single populated center with about 185,000 residents. Pampa, Texas, located about 40 miles northeast of the plant, is second in population density with about 21,000 residents. The remaining population is distributed throughout smaller communities, farms, and ranches. Although there is a variety of industries in the area, the local economy is influenced most significantly by agriculture and related industries.

Wheat and grain sorghums are the major field crops in the area with cattle ranching and cattle feeding also serving a large portion of the local economy. 


\section{SUMMARY}

During 1977 Pantex Plant released quantities of radioactive and nonradioactive pollutants (see Tables I and XXVII respectively).
Using the calculational method on Page 8 it was found that the dose within an 80 kilometer boundary due to Pantex activities was $4 \times 10^{-7}$ person-rem for ${ }^{238} \mathrm{U}$ and $2 \times 10^{-4}$ person-rem for ${ }^{3} \mathrm{H}$. Further results are shown in Table V.

\section{ENVIRONMENTAL MONITORING}

During 1977 Pantex Plant continued its environmental monitoring program which entailed the analysis of air, water, soil, vegetation, and specific biota. The most notable aspect of the environmental monitoring program was the detection of fallout from Chinese weapons tests which occurred September 17 . Since fission products are not specifically identified in the Pantex environmental monitoring analyses, the fallout was detected primarily as gross beta activity. Activity from the fallout, while many times above background, does not represent an immediate hazard to local inhabitants and has subsided through natural decay and atmospheric dillution.

Air samples were obtained from eleven off-site continuously operating air collection devices which were equipped with particulate and water vapor collectors (Ref. Figure 4). These air samples were analyzed for gross alpha, gross beta, total uranium, plutonium-239, and tritium. The results of these analyses indicate that airborne radioactivity in the vicinity of the Pantex facility was well within established radioactivity concentration guides (RCG).

The activity that was observed is believed to be largely a result of natural radioactivity and worldwide fall-out from atomic or nuclear weapons tests (principally those of the Chinese) and not from Pantex Plant activities.
Water sampling was performed for ground water from Pantex wells, an off-site playa located north of the facility and for the on-site retention playa which collects all industrial and treated sanitary effluents prior to use in crop irrigation.

The data on radioactivity in water do not indicate the presence of radioactivity discernible above natural levels.

Soil samples were collected and subjected to analysis for total uranium, plutonium-239, and tritium content at locations indicated on Figure 5.

There are no official RCG's for radionuclides in soil. The concentrations resulting from analyses of the local soil for plutonium-239 show that local levels are indistinguishable from world-wide fallout. Tritium and tota1 uranium analyses are also consistent with what is considered natural activity.

Analysis of vegetation to determine total uranium and tritium concentrations was performed to determine whether unusual uptake of uranium or tritium from the soil or air had occurred. As with soil there are no established RCG's for uranium or tritium in vegetation although RCG's for water are sometimes used for purposes of comparison.

The data in Tables XXI and XXII are consistent with past data on vegetation and do not indicate any upward trend. Local 
vegetation naturally contains uranium in concentrations comparable with those in Table XXI.

Since 1974 the jackrabbit (Lepus californicus Gray) has been used for analysis in the environmental monitoring program. The jackrabbit was chosen as the subject because of its abundance, its prolific nature, and its habit of maintaining a limited range as long as food is available.

of the three types of analysis performed on the jackrabbits, only the uranium data showed concentrations above the detection limit (Ref. Tables XXIII, XXIV and XXV.

The individual organ mass is provided in Table XXVI to assist in the evaluation of organ doses if desired.

On the basis of the estimated quantities of uranium-238 and tritium released during 1977 (Ref. Table I) the associated average concentrations and dose equivalents were calculated for persons residing within an 80 kilometer radius of Pantex Plant. Dose calculations for the site boundary and nearest inhabitants include kidney dose as well as total body dose equivalent since the kidney is the critical organ for uranium-238 exposure. The total body dose for all persons residing within an 80 kilometer radius of the Pantex Plant is expressed in person-rem.

Meteorological observations from the National Weather Service Office at the Amarillo Air Terminal were utilized in construction of a resultant wind rose for the Pantex vicinity. This, together with associated climatological data is utilized as input to a computer model for calculation of uranium and tritium concentrations within the 80 kilometer radius.
The computer model utilized for calculation of contaminant contributions is the Climatological Dispersion Mode1 (CDM) written by the National Environmental Research Center of the U.S. Environmenta1 Protection Agency(7).

The uranium and tritium concentrations in Table III were used in calculating the dose values in Table V. For the uranium calculations separate RCG's and associated doses were used for the total body and kidney determinations since the limiting dose equivalent is different in each case.

\section{AIR}

$\underline{\text { Radioactive }}$

Environmenta1 air sampling is accomplished through the use of eleven continuously operating air samplers nine of which are located around an approximate 5-mile radius of Pantex plant (Ref. Figure 4).

These samplers are equipped with air pumps that operate continuously at a collection rate of $\sim 28 \mathrm{l} / \mathrm{min}$. Particulates are collected on a 47 millimeter diameter membrane filter which is collected nominally on a weekly basis. Although severe weather and other factors influence collection frequency, a typical weekly air sample will represent about 600 cubic meters of air.

A silica gel column is included in the sampling line for collection of environmental tritium oxide. The silica gel, acting as a desiccant, removes water vapor from the air stream following removal of the particulates. Any tritium oxide present will be captured with the water vapor and may be recovered for analysis at some later date. Silica gel columns are exchanged on the same frequency as the air filters. 
Each weekly air sample is evaluated for gross alpha and gross beta activity then composited on a monthly basis with other filters from the same air sampling station. These samples are then sent to an outside laboratory for total uranium and plutonium-239 analysis. Silica gel samples are also analyzed by an outside laboratory to determine tritium oxide content but are not composited as were the air filters.

A summary of the results for gross alpha, gross beta, uranium, plutonium-239 and tritium oxide in air is presented in Tables VI, VII and VIII. Upwind sample stations Nos. 11 and 12 are considered to be representative of background since they were taken well off the Pantex Plant site on the predominantly upwind side. Deviations above background are attributed to the Chinese weapons test and natural meterological distribution.

Non-Radioactive

Pantex Plant does not have any industrial processes which serve as significant sources of particulate matter, carbon monoxide, photochemical oxidants, hydrocarbons, oxides of nitrogen, or oxides of sulfur. Steam is generated by natural gas-fired boilers which are low in sulfur dioxide emissions (see Appendix). Other sources of pollutants are generally absent since most of the work performed is mechanical rather than chemical. Estimated emissions from Pantex Plant steam generation operations during 1977 are presented in Table II.

Some emissions occur from test fires of chemical high explosives, burning of waste high explosives and "flashing" of high explosives contaminated scrap metal. These operations occur so infrequently, however, (a few hours per week) that off-site environmental sampling for related non-radioactive contaminants is not performed. During 1977 an estimated $82,500 \mathrm{~kg}$ of waste chemical high explosives were burned and approximately 30,000 litres of toluene were disposed of by evaporation.

\section{WATER}

\section{Radioactive}

Local geologic characteristics of the Pantex vicinity are such that there are no streams or rivers which flow through or near the plant site. Plant effluents flow into an on-site playa (designated WS-8 on Fig. 5) prior to use for irrigation.

This on-site retention playa, a nearby natural playa (WS-1), and groundwater from plant wel1s (WS-2, WS-6, and WS-7) are the only available locations for collecting environmental water samples. Plant we1ls include deep water wells from the Ogallala aquifer and two special sha1low test wells designated WS-19 and WS-20. Playa water is not considered potable as it is high in natural dissolved alkali salts. The nearby natural playa was dry during most of 1977 , which accounts for the small number of samples taken at that sampling site.

From the sources available one-gallon water samples are collected monthly and sent to an outside laboratory for analysis of dissolved alpha, suspended alpha, dissolved beta, suspended beta, total uranium, plutonium-239, and tritium oxide content. A summary of these data for 1977 is presented in Tables XI through XVII.

Non-Radioactive

Analysis of environmental water samples is also accomplished for non- 
nonradioactive species but on a quarterly rather than monthly basis. Most of the actual analytical work is performed by an outside laboratory and comparisons are made with Environmental Protection Agency and Federal Water Pollution Control Agency standards.

A summary of analysis for nonradioactive species for 1977 is presented in Table XXVII.

The average level of $\mathrm{SO}_{4}$ for the retention playa is $57.9 \mathrm{mg} / \ell$. This exceeds the criteria for irrigation by less than $8 \mathrm{mg} / \ell$. The main source of sulfates is due to the salt formed in the chemical reaction between the sulfuric acid and the caliche which is used to neutralize the sulfuric acid wastes.

The average level of fecal coliforms for the sewage treatment discharge is 6863.9 counts $/ 100 \mathrm{ml}$. This exceeds the EPA Secondary Treatment Regulation Criteria which is 200 counts/me. The high count was due to mechanical breakdown of the chlorinator and difficulty of getting replacement parts.

\section{SOIL}

\section{$\underline{\text { Radioactive }}$}

Thirty-one environmental soil samples are collected monthly at the locations indicated in Figure 5 according to standard soil sampling protocol. Each sample consists of two plugs from a "cookie cutter" which is 8.9 centimeters in diameter and 5.1 centimeters in depth. A sample may also contain a small amount of roots/vegetation.

After collection, the samples are sent to an outside laboratory where any uranium, plutonium, or tritium is chemically extracted according to standard methods and then analyzed to determine the amount of each isotope of interest.

A summary of soil sampling results is presented in Tables XVIII, XIX and $\mathrm{XX}$ for uranium, plutonium-239, and tritium oxide respectively.

\section{Non-Radioactive}

No environmental sampling for nonradioactive contaminants in soil was performed during 1977.

\section{VEGETATION}

\section{Radioactive}

Environmental vegetation samples are collected from 16 locations (Ref. Figure 5) each month for analysis of total uranium and tritium oxide content. These samples consist primarily of native and domestic grasses although it is not unconmon for a small percentage of other vascular plants to be present in some samples.

Following collection and labeling the samples are sent to an outside laboratory for the actual analysis. The analytical procedures used are essentially the same as for analysis of nuclides in soil and a summary of the results is presented in Tables XVI and XVII.

Non-Radioactive

Analysis of environmental vegetation samples for non-radioactive contaminants was not performed during 1977. 
BIOTA

\section{$\underline{\text { Radioactive }}$}

During 1977 ten jackrabbits (Lepus californicus Gray) were collected from within the plant perimeter and analyzed for the presence of uranium, plutonium-239, and tritium oxide. The locations where the specimens were collected were chosen carefully to help determine whether other than natural levels of uranium, plutonium239 , or tritium oxide were present in the biological cycle.

Following collection the specimens were frozen and sent to an independent laboratory where dissection and analyses of lung, liver, kidney, bone, and muscle tissue were performed to determine the quantity of uranium, plutonium-239, and tritium oxide present in each organ.

These data are presented in their entirety in Tables XXIII, XXIV, and $\mathrm{XXV}$.

Non-Radioactive

The analysis of biota for the presence of non-radioactive species was not performed during 1977. 


\section{CALCULATION OF POTENTIAL RAOIATION DOSE TO THE \\ PUBLIC FROM PANTEX ACTIVITIES FOR 1977}

Radiation exposure to the public from Pantex activities is minimal. An estimation of the overall impact to the public from routine activities was made by application of atmospheric diffusion calculations to estimated average annual radioactivity release rates using local meteorological data.

Table I provides estimated curies of depleted uranium and tritium released during 1977. These releases are considered ground level releases since the uranium and tritium were released from structures or facilities not having stacks. Average resultant wind speed and directional frequency (Ref. Figure 3) were determined for each of the sixteen compass points using official climatological data for Amarillo, Texas, for 1977(8).

Population estimates were based on figures presented in the Texas Almanac for each city, town, and county within an 80 kilometer radius of Pantex Plant $(6,9)$.

The computer model utilized in describing local atmospheric dispersion utilizes six atmospheric stability classes and six wind speed classes to describe the atmospheric characteristics of the sixteen wind sectors contained within the 80 kilometer radius. Meteorological parameters were chosen from data obtained at the Amarillo Office of the National Weather Service and utilized as input parameters for the Climatological Dispersion Mode1 (CDM). Following input of approximate parameters, source data, and receptor points, the CDM calculates average annual concentration of contaminants at each receptor point.
Estimated dose equivalents from the inhalation of depleted uranium and tritium were evaluated according to equation (1) which uses a simple ratio of the calculated concentration to the appropriate RCG as the basis for dose determination:

$$
D_{x}=\frac{x \cdot D}{R C G}
$$

Where

$$
\begin{aligned}
\mathrm{D}_{\mathrm{X}}= & \begin{array}{l}
\text { dose to critical organ in } \\
\text { rem }
\end{array} \\
\mathrm{X}= & \begin{array}{l}
\text { concentration of nuclide } \\
\text { (Ref. Table III) }
\end{array} \\
\mathrm{RCG}= & \begin{array}{l}
\text { RCG for uncontrolled area } \\
\text { expressed in curies/cubic } \\
\\
\text { meter }(10)
\end{array} \\
\mathrm{D}= & \begin{array}{l}
\text { dose to critical organ } \\
\text { associated with the appro- } \\
\text { priate RCG }(10)
\end{array}
\end{aligned}
$$
$\mathrm{D}=$ dose to critical organ associated with the appro- priate $\mathrm{RCG}(10)$

For Pantex operations, three groups of receptors were chosen in performing dose calculations: (a) hypothetical site boundary receptors, (b) nearest inhabitants to the plant reservation, and (c) cities, towns, and communities within an 80 kilometer radius of Pantex Plant. Dose estimates are expressed in rem or person-rem where the term person-rem refers to the product of dose times population for the various receptor groups.

The 80 kilometer person-rem is determined according to contaminant concentration and population in sixteen sectors (Ref. Figure 6) as described by equation (2): 


$$
D_{80}=\sum_{n=1}^{K} \frac{x_{n} D_{w b} P_{n}}{\mathrm{RCG}_{w b}}
$$

where

$$
\begin{aligned}
D_{80}= & 80-k i l o m e t e r \text { total body } \\
& \text { dose in person-rem } \\
x_{n}= & \text { average concentration for } \\
& \text { each receptor location } \\
& \text { (Ref. Table IV) }
\end{aligned}
$$

$$
\begin{aligned}
\mathrm{RCG}_{\mathrm{wb}}= & \text { radioactivity concentration } \\
& \text { guide associated with the } \\
& \text { whole body as the critica1 } \\
& \text { organ }
\end{aligned}
$$

$D_{\mathrm{wb}}=$ dose to whole body associated with the appropriate RCG

$\mathrm{P}_{\mathrm{n}}=$ population for receptor location considered (Ref. Table III)

$\mathrm{K}=$ number of receptor locations 


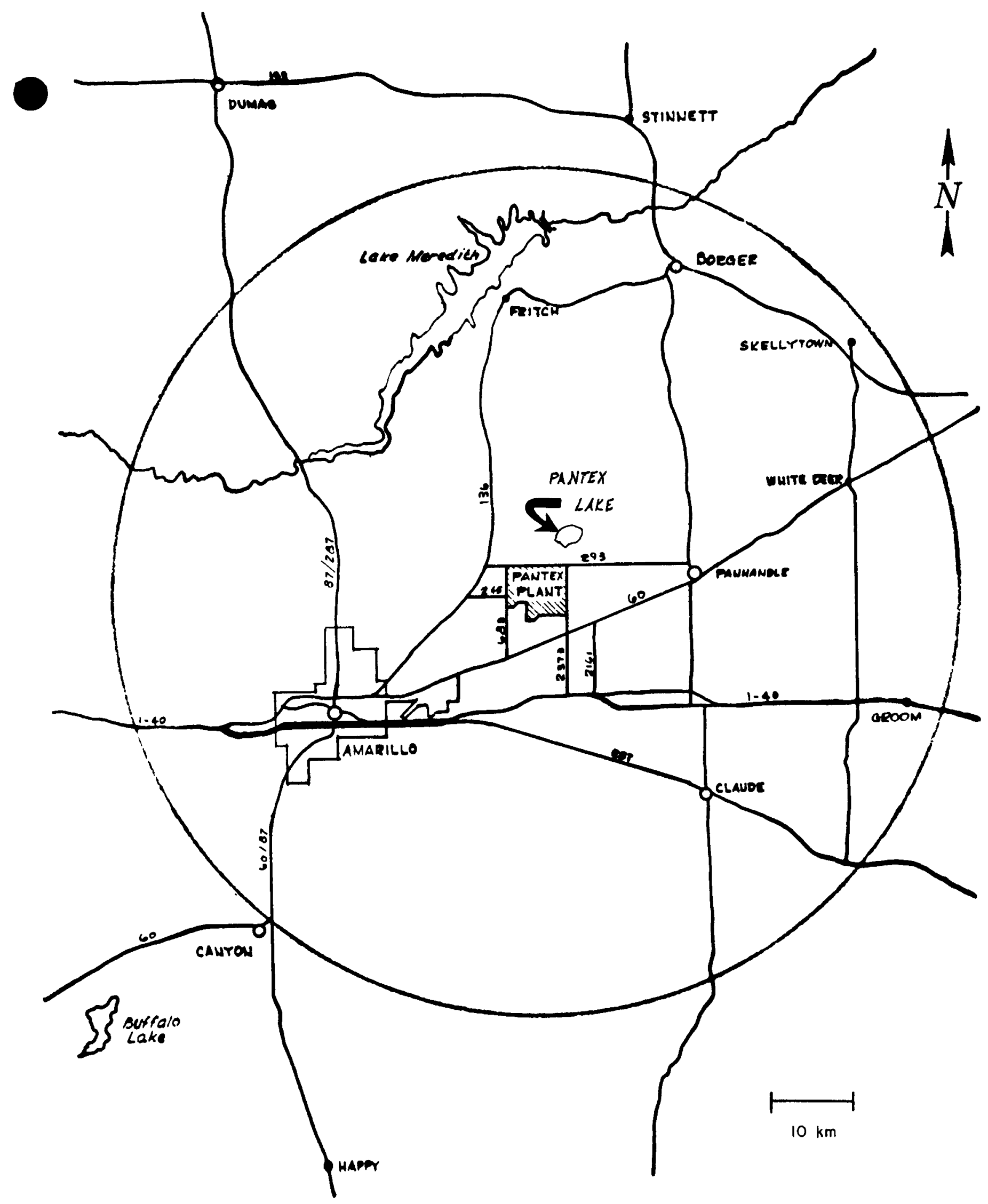

Figure 1. Pantex Plant 30 Mile (48-kilometer) Vicinity Map 


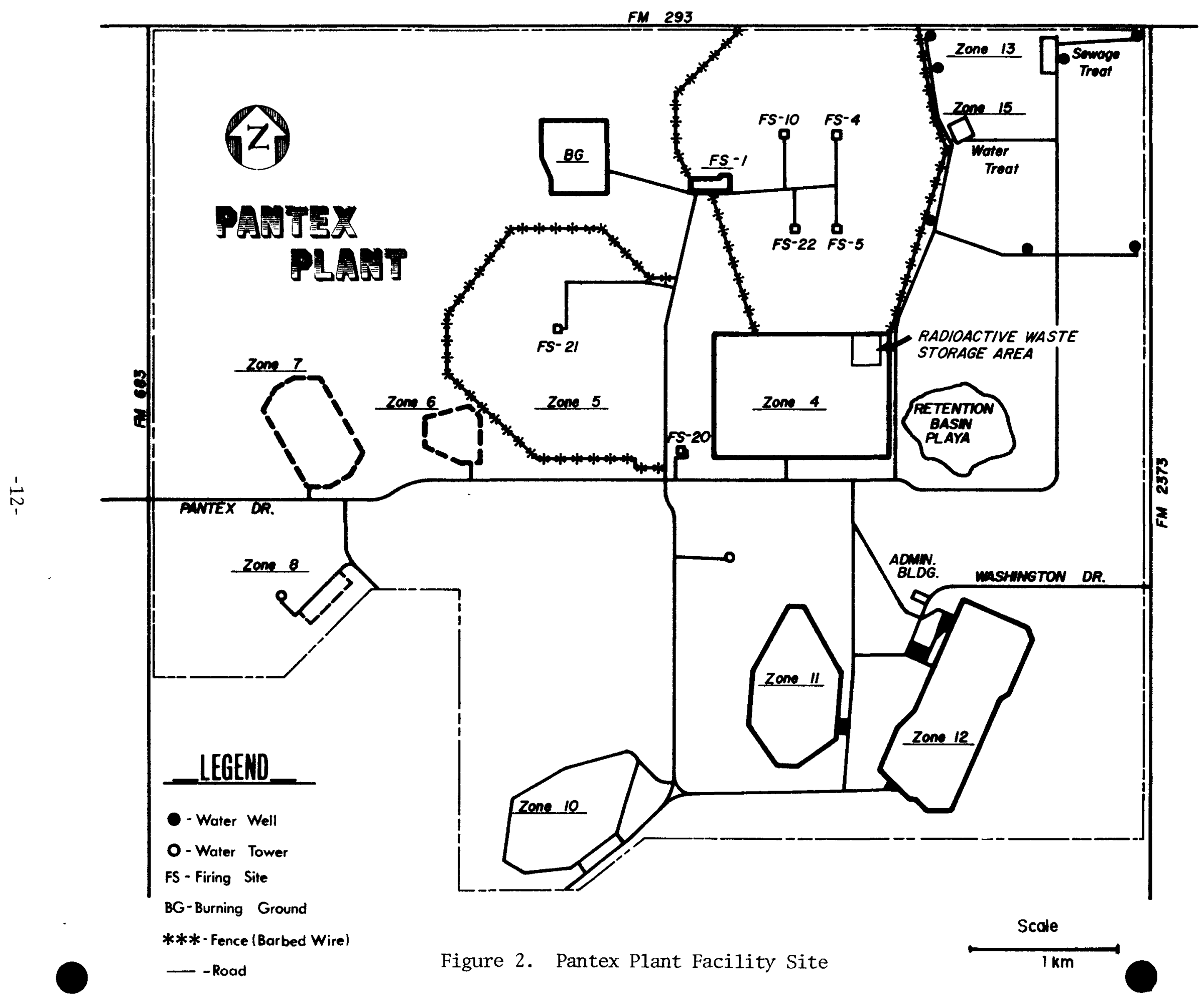




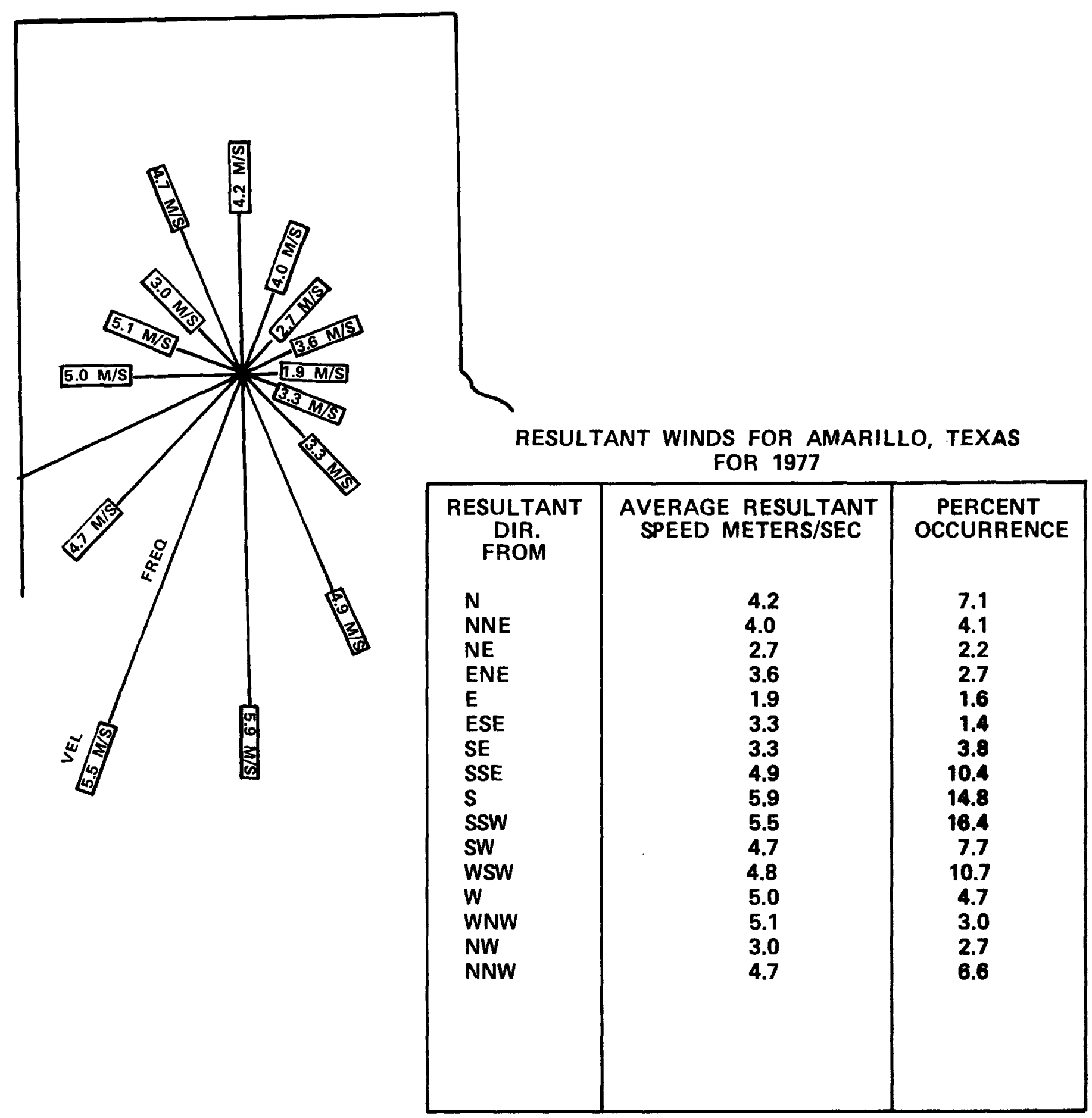

FIGURE 3. RESULTANT WINDS FOR AMARILLO, TEXAS FOR 1977 


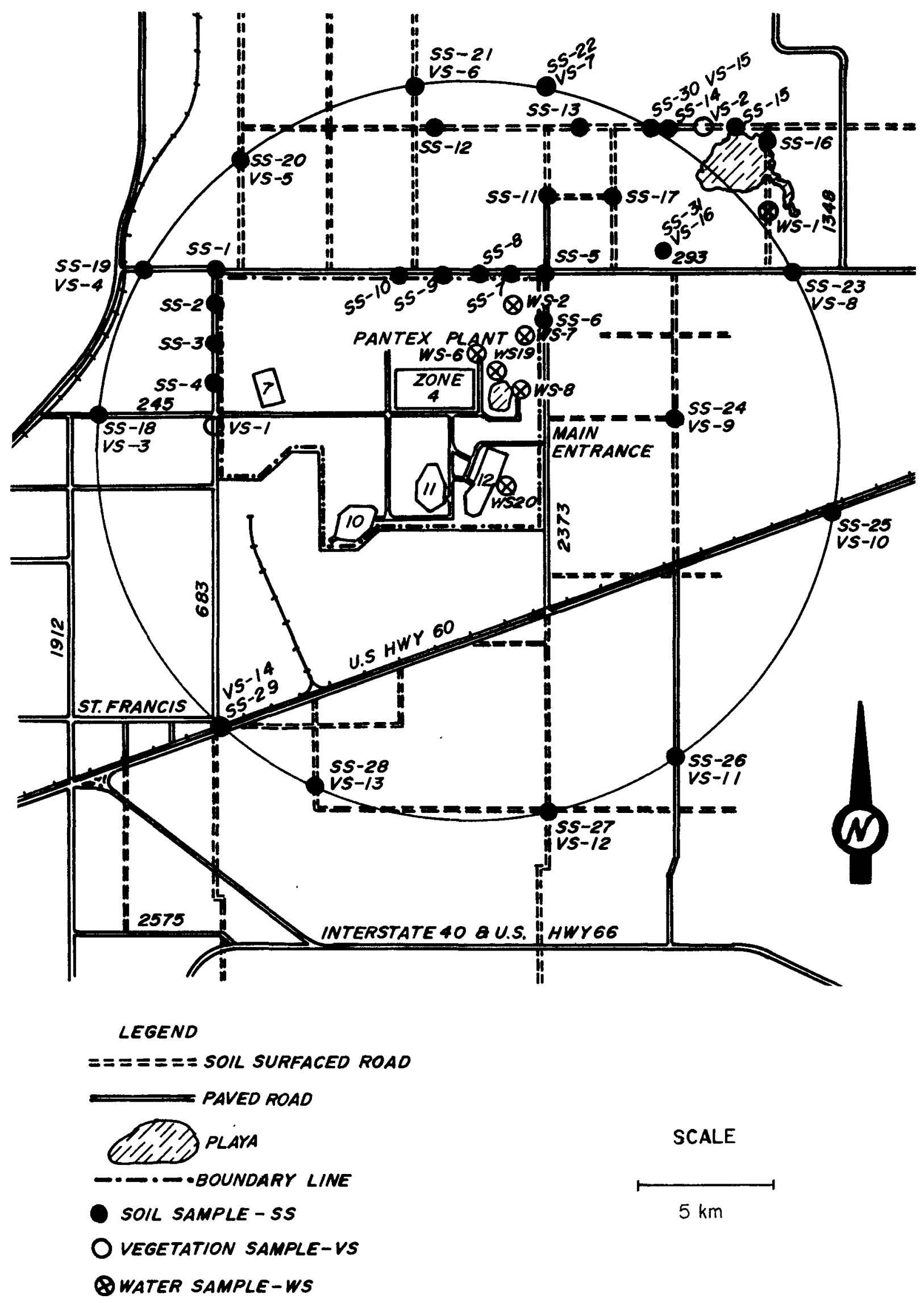

Figure 5. Environmenta1 Soil, Water and Vegetation Sampling Locations for Pantex Plant 


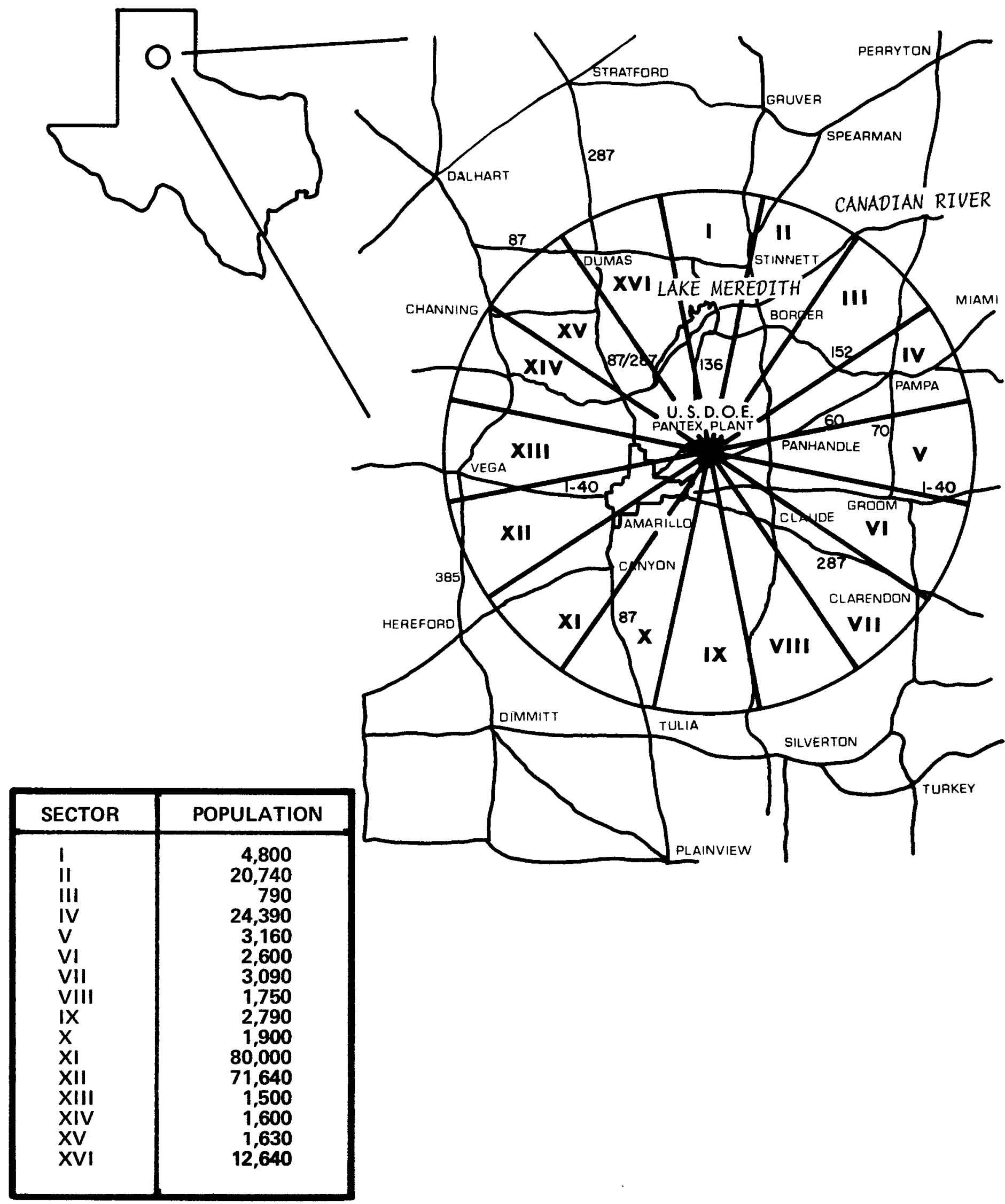

Figure 6. Population Within an 80 Kilometer Radius of Pantex Plant $-16-$ 
Table I. Estimated Atmospheric Releases of Radioactive Material from Pantex for 1977

\begin{tabular}{lcc}
\multicolumn{1}{c}{ Nuclide } & Curies & $\begin{array}{c}\text { Average } \\
\text { Source Emission } \\
\text { (Curies/Second)* }\end{array}$ \\
$\begin{array}{l}\text { Pepleted Uranium }\left({ }^{238} \mathrm{U}\right) \\
\left.\text { Tritium ( }{ }^{3} \mathrm{H}\right)\end{array}$ & $1 \times 10^{-3}$ & $3 \times 10^{-11}$ \\
${ }^{*}$ Average over one year (3.16 $\times 10^{7}$ seconds)
\end{tabular}

Table II. Estimated Steam Generating Plant Emissions for 1977

Contaminant

Carbon Monoxide

Oxides of Nitrogen
Release

(metric tons)

13

59 
Table III. Population of Area Receptors Used in 1977 Uranium and Tritium Calculations

\begin{tabular}{|c|c|c|c|c|c|}
\hline Receptor & Sector & Population & Receptor & Sector & Population \\
\hline Fritch & I & 1,795 & Claude & VIII & 1,017 \\
\hline Sanford & I & 185 & Rura1/Suburban & VIII & 831 \\
\hline Stinnett & I & 2,025 & \multirow{3}{*}{$\begin{array}{l}\text { Wayside } \\
\text { Rural/Suburban }\end{array}$} & \multirow{3}{*}{$\begin{array}{l}\text { IX } \\
\text { IX }\end{array}$} & \multirow{3}{*}{$\begin{array}{r}40 \\
2,774\end{array}$} \\
\hline Rural/Suburban & I & 795 & & & \\
\hline Buena Vista & II & 1,410 & & & \\
\hline Borger & II & 14,560 & Washburn & $\mathrm{x}$ & 70 \\
\hline Phillips & II & 2,540 & Happy & $\mathrm{X}$ & 680 \\
\hline Rural/Suburban & II & 2,234 & Rura1/Suburban & $\mathrm{X}$ & 1,127 \\
\hline Skellytown & III & \multirow{2}{*}{$\begin{array}{r}701 \\
91\end{array}$} & Canyon & XI & 8,758 \\
\hline Rura1/Suburban & III & & Umbarger & XI & 327 \\
\hline Pampa & IV & 20,979 & \multirow{2}{*}{ Rura1/Suburban } & \multirow{2}{*}{$\mathrm{XI}$} & \multirow{2}{*}{$\begin{array}{r}94 \\
3,816\end{array}$} \\
\hline White Deer & IV & 1,102 & & & \\
\hline Kings Mill & IV & 65 & Amarillo & XII & $\begin{array}{r}34,576 \\
130\end{array}$ \\
\hline Rura1/Suburban & IV & 2,240 & $\begin{array}{l}\text { Bushland } \\
\text { Wildorado }\end{array}$ & XII & $\begin{array}{l}130 \\
180\end{array}$ \\
\hline Panhandle & V & 2,190 & Rura1/Suburban & XII & $4, \overline{328}$ \\
\hline Lefors & V & 816 & & & \\
\hline Alanreed & V & 60 & Vega & XIII & 839 \\
\hline Rura1/Suburban & V & 92 & Rural/Suburban & XIII & 668 \\
\hline Groom & VI & 808 & Channing & XIV & 352 \\
\hline Jerico & VI & 100 & & XIV & \multirow{3}{*}{841} \\
\hline Lark & VI & 26 & \multirow[t]{2}{*}{ Rural/Suburban } & \multirow[t]{2}{*}{ XIV } & \\
\hline \multirow{2}{*}{ Rura1/Suburban } & VI & 1,669 & & & \\
\hline & & & Masterson & $X V$ & 85 \\
\hline Conway & VII & 50 & Rura1/Suburban & XV & 1,541 \\
\hline Asholta & VII & 20 & & & \\
\hline Clarendon & VII & 2,400 & Dumas & XVI & 9,850 \\
\hline Goodnight & VII & 25 & $\mathrm{Ru}$ & $x \vee 1$ & 191 \\
\hline Rural/Suburban & VII & 646 & & & \\
\hline
\end{tabular}


Table IV. Calculated Uranium-in-Air and Tritium-in-Air

Contributions from Pantex Plant for 1977

\begin{tabular}{|c|c|c|c|c|}
\hline Receptor & $\begin{array}{c}\text { Calculated Tritium } \\
\text { Contribution } \\
\left(\mu \mathrm{Ci} / \mathrm{m} \ell \times 10^{-19}\right) \\
\end{array}$ & $\because \mathrm{RCG}$ & $\begin{array}{l}\text { Calculated Uranium } \\
\text { Contribution } \\
\left(\mu \mathrm{Ci} / \mathrm{ml} \times 10^{-19}\right) \\
\end{array}$ & $\because \mathrm{RCG}$ \\
\hline $\begin{array}{l}\text { Fritch } \\
\text { Sanford } \\
\text { Stinnett } \\
\text { Rural/Suburban Sector I }\end{array}$ & $\begin{array}{l}3 \\
5 \\
3 \\
4\end{array}$ & $\begin{array}{l}3 \times 10^{-10} \\
5 \times 10^{-10} \\
3 \times 10^{-10} \\
4 \times 10^{-10}\end{array}$ & $\begin{array}{l}2 \\
4 \\
2 \\
3\end{array}$ & $\begin{array}{lll}2 & \times & 10^{-5} \\
4 & \times & 10^{-5} \\
2 & \times & 10^{-5} \\
3 & \times & 10^{-5}\end{array}$ \\
\hline $\begin{array}{l}\text { Buena Vista } \\
\text { Borger } \\
\text { Phillips } \\
\text { Rural/Suburban Sector II }\end{array}$ & $\begin{array}{l}3 \\
3 \\
2 \\
2\end{array}$ & $\begin{array}{l}3 \times 10^{-10} \\
3 \times 10^{-10} \\
2 \times 10^{-10} \\
2 \times 10^{-10}\end{array}$ & $\begin{array}{l}2 \\
2 \\
2 \\
2\end{array}$ & $\begin{array}{lll}2 & \times & 10^{-5} \\
2 & \times & 10^{-5} \\
2 & \times & 10^{-5} \\
2 & \times & 10^{-5}\end{array}$ \\
\hline $\begin{array}{l}\text { Ske1lytown } \\
\text { Rural/Suburban Section III }\end{array}$ & $\begin{array}{l}2 \\
1\end{array}$ & $\begin{array}{l}2 \times 10^{-10} \\
1 \times 10^{-10}\end{array}$ & $\begin{array}{l}2 \\
1\end{array}$ & $\begin{array}{l}2 \times 10^{-5} \\
1 \times 10^{-5}\end{array}$ \\
\hline $\begin{array}{l}\text { Pampa } \\
\text { White Deer } \\
\text { Kings Mill } \\
\text { Rural/Suburban Section IV }\end{array}$ & $\begin{array}{l}0.8 \\
1 \\
2 \\
0.9\end{array}$ & $\begin{array}{r}0.8 \times 10^{-10} \\
1 \times 10^{-10} \\
2 \times 10^{-10} \\
0.9 \times 10^{-10}\end{array}$ & $\begin{array}{l}0.6 \\
0.9 \\
1 \\
0.7\end{array}$ & $\begin{array}{r}0.8 \times 10^{-5} \\
0.9 \times 10^{-5} \\
1 \times 10^{-5} \\
0.7 \times 10^{-5}\end{array}$ \\
\hline $\begin{array}{l}\text { Panhandle } \\
\text { Lefors } \\
\text { Alanreed } \\
\text { Rural/Suburban Sector V }\end{array}$ & $\begin{array}{l}2 \\
9 \\
1 \\
1\end{array}$ & $\begin{array}{l}2 \times 10^{-10} \\
9 \times 10^{-10} \\
1 \times 10^{-10} \\
1 \times 10^{-10}\end{array}$ & $\begin{array}{l}1 \\
7 \\
0.9 \\
0.7\end{array}$ & $\begin{array}{r}1 \times 10^{-5} \\
7 \times 10^{-5} \\
0.9 \times 10^{-5} \\
0.7 \times 10^{-5}\end{array}$ \\
\hline $\begin{array}{l}\text { Groom } \\
\text { Jerico } \\
\text { Lark } \\
\text { Rura1/Suburban Sector VI }\end{array}$ & $\begin{array}{l}0.6 \\
0.6 \\
2 \\
0.5\end{array}$ & $\begin{array}{l}0.6 \times 10^{-10} \\
0.6 \times 10^{-10} \\
2 \times 10^{-10} \\
0.5 \times 10^{-10}\end{array}$ & $\begin{array}{l}0.5 \\
0.4 \\
1 \\
0.3\end{array}$ & $\begin{array}{r}0.5 \times 10^{-5} \\
0.4 \times 10^{-5} \\
1 \times 10^{-5} \\
0.3 \times 10^{-5}\end{array}$ \\
\hline $\begin{array}{l}\text { Conway } \\
\text { Ashtola } \\
\text { Clarendon } \\
\text { Goodnight } \\
\text { Rural/Suburban Sector VII }\end{array}$ & $\begin{array}{c}0.7 \\
11 \\
3 \\
2 \\
2\end{array}$ & $\begin{array}{r}0.7 \times 10^{-10} \\
11 \times 10^{-10} \\
3 \times 10^{-10} \\
2 \times 10^{-10} \\
2 \times 10^{-10}\end{array}$ & $\begin{array}{l}0.5 \\
9 \\
2 \\
2 \\
2\end{array}$ & $\begin{array}{r}0.5 \times 10^{-5} \\
9 \times 10^{-5} \\
2 \times 10^{-5} \\
2 \times 10^{-5} \\
2 \times 10^{-5}\end{array}$ \\
\hline $\begin{array}{l}\text { Claude } \\
\text { Rural/Suburban Sector VIII }\end{array}$ & $\begin{array}{l}3 \\
4\end{array}$ & $\begin{array}{l}3 \times 10^{-10} \\
4 \times 10^{-10}\end{array}$ & $\begin{array}{l}2 \\
3\end{array}$ & $\begin{array}{l}2 \times 10^{-5} \\
3 \times 10^{-5}\end{array}$ \\
\hline $\begin{array}{l}\text { Wayside } \\
\text { Rural/Suburban Sector IX }\end{array}$ & $\begin{array}{r}10 \\
6\end{array}$ & $\begin{aligned} 10 \times 10^{-10} \\
7 \times 10^{-10}\end{aligned}$ & $\begin{array}{l}7 \\
4\end{array}$ & $\begin{array}{l}7 \times 10^{-5} \\
4 \times 10^{-5}\end{array}$ \\
\hline $\begin{array}{l}\text { Washburn } \\
\text { Happy } \\
\text { Rura1/Suburban Sector X }\end{array}$ & $\begin{array}{r}3 \\
13 \\
6\end{array}$ & $\begin{aligned} 3 \times 10^{-10} \\
13 \times 10^{-10} \\
6 \times 10^{-10}\end{aligned}$ & $\begin{array}{r}2 \\
10 \\
5\end{array}$ & $\begin{aligned} 2 & \times 10^{-5} \\
10 & \times 10^{-5} \\
5 & \times 10^{-5}\end{aligned}$ \\
\hline $\begin{array}{l}\text { Canyon } \\
\text { Umbarger } \\
\text { Dawn } \\
\text { Rura1/Suburban Sector XI }\end{array}$ & $\begin{array}{l}3 \\
3 \\
3 \\
6\end{array}$ & $\begin{array}{l}3 \times 10^{-10} \\
3 \times 10^{-10} \\
3 \times 10^{-10} \\
6 \times 10^{-10}\end{array}$ & $\begin{array}{l}2 \\
3 \\
2 \\
5\end{array}$ & $\begin{array}{lll}2 & \times & 10^{-5} \\
3 & \times & 10^{-}-5 \\
2 & \times & 10^{-5} \\
5 & \times & 10^{-5}\end{array}$ \\
\hline
\end{tabular}


Table IV. Cont'd

\begin{tabular}{|c|c|c|c|c|}
\hline Receptor & $\begin{array}{c}\text { Calculated Tritium } \\
\text { Contribution } \\
\left(\mu \mathrm{Ci} / \mathrm{m \ell} \times 10^{-19}\right) \\
\end{array}$ & $\%$ RCG & $\begin{array}{c}\text { Calculated Uranium } \\
\text { Contribution } \\
\left(\mu \mathrm{C} i / \mathrm{m} \ell \times 10^{-19}\right) \\
\end{array}$ & $\because$ RCG \\
\hline $\begin{array}{l}\text { Amarillo } \\
\text { Bushland } \\
\text { Wildorado } \\
\text { Rural/Suburban Sector XII }\end{array}$ & $\begin{array}{l}3 \\
6 \\
3 \\
5\end{array}$ & $\begin{array}{l}3 \times 10^{-10} \\
6 \times 10^{-10} \\
3 \times 10^{-10} \\
5 \times 10^{-10}\end{array}$ & $\begin{array}{l}2 \\
4 \\
3 \\
3\end{array}$ & $\begin{array}{l}2 \times 10^{-5} \\
4 \times 10^{-5} \\
3 \times 10^{-5} \\
3 \times 10^{-5}\end{array}$ \\
\hline $\begin{array}{l}\text { Vega } \\
\text { Rura1/Suburban Sector XIII }\end{array}$ & $\begin{array}{l}1 \\
5\end{array}$ & $\begin{array}{l}1 \times 10^{-10} \\
5 \times 10^{-10}\end{array}$ & $\begin{array}{l}1 \\
4\end{array}$ & $\begin{array}{l}1 \times 10^{-5} \\
4 \times 10^{-5}\end{array}$ \\
\hline $\begin{array}{l}\text { Channing } \\
\text { Boys Ranch } \\
\text { Rural/Suburban Sector XIV }\end{array}$ & $\begin{array}{l}0.7 \\
1 \\
1\end{array}$ & $\begin{array}{r}0.7 \times 10^{-10} \\
1 \times 10^{-10} \\
1 \times 10^{-10}\end{array}$ & $\begin{array}{r}0.5 \\
1 \\
1\end{array}$ & $\begin{array}{r}0.5 \times 10^{-5} \\
1 \times 10^{-5} \\
1 \times 10^{-5}\end{array}$ \\
\hline $\begin{array}{l}\text { Masterson } \\
\text { Rural/Suburban Sector XV }\end{array}$ & $\begin{array}{l}1 \\
2\end{array}$ & $\begin{array}{l}1 \times 10^{-10} \\
2 \times 10^{-10}\end{array}$ & $\begin{array}{r}0.6 \\
1\end{array}$ & $\begin{array}{r}0.6 \times 10^{-5} \\
1 \times 10^{-5}\end{array}$ \\
\hline $\begin{array}{l}\text { Dumas } \\
\text { Rura1/Suburban Sector XVI }\end{array}$ & $\begin{array}{l}2 \\
3\end{array}$ & $\begin{array}{l}2 \times 10^{-10} \\
3 \times 10^{-10}\end{array}$ & $\begin{array}{l}2 \\
2\end{array}$ & $\begin{array}{l}2 \times 10^{-5} \\
2 \times 10^{-5}\end{array}$ \\
\hline Nearest Inhabitant & 3 & $3 \times 10^{-10}$ & 2 & $2 \times 10^{-5}$ \\
\hline Site' Boundary & 4 & $4 \times 10^{-10}$ & 3 & $3 \times 10^{-5}$ \\
\hline * Radioactivity Concentratio & on Guide $=\begin{array}{rll}1 & x & 10^{-12} \\
1 & x & 10^{-7}\end{array}$ & $\begin{array}{l}\mu C i / m e \text { for } \\
\mu C i / m e \text { for }\end{array}$ & $\begin{array}{l}238 U \text { and } \\
{ }^{3} H\end{array}$ & - \\
\hline
\end{tabular}


Table V. Pantex Vicinity Dose Calculation for 1977

Reference Point

Site Boundary

Total Body

Kidney

Lung $\underline{\text { Uranium }(238 \mathrm{U})}$

$3 \times 10^{-9}$ Rem

$2 \times 10^{-7}$ Rem

$9 \times 10^{-8}$ Rem

Nearest Individual

Total Body

Kidney

Lung
$2 \times 10^{-9}$ Rem

$1 \times 10^{-7}$ Rem

$6 \times 10^{-8}$ Rem

$\underline{\text { Tritium }\left({ }^{3} \mathrm{H}\right)}$

$1 \times 10^{-12}$ Rem

N/A

N/A

80 Kilometer

Total Body

$4 \times 10^{-4}$ Person-Rem

$8 \times 10^{-13}$ Rem
N/A
N/A

*For Uranium-238, the kidney is the eritical organ, the total body is the critical organ for Tritium exposures. Total body RCG's were used in total body and person-rem determinations. 
Table VI. Summary of Gross Alpha Activity in Air for 1977

\begin{tabular}{|c|c|c|c|c|}
\hline $\begin{array}{l}\text { Sample } \\
\text { Station }\end{array}$ & $\begin{array}{l}\text { Number } \\
\text { Samples } \\
\end{array}$ & $\begin{array}{l}\text { Average } \mu \mathrm{Ci} / \mathrm{m} \ell \\
\left(10^{-16}\right)\end{array}$ & $\begin{array}{l}\text { Maximum } \mu \mathrm{Ci} / \mathrm{m} \ell \\
\frac{\left(10^{-16}\right)}{} \\
\end{array}$ & $\begin{array}{l}\text { Minimm } \mu \mathrm{Ci} / \mathrm{m} \ell \\
\left(10^{-16}\right) \\
\end{array}$ \\
\hline 1 & 23 & $6.13 \pm 4.57$ & $19.14 \pm 7.06$ & $0.0 \pm 2.84$ \\
\hline 2 & 27 & $6.99 \pm 4.77$ & $21.75 \pm 7.14$ & $0.0 \pm 2.36$ \\
\hline 3 & 47 & $5.98 \pm 4.54$ & $27.33 \pm 7.04$ & $0.0 \pm 2.36$ \\
\hline 4 & 24 & $3.99 \pm 4.33$ & $12.98 \pm 5.54$ & $0.0 \pm 1.11$ \\
\hline 5 & 47 & $6.08 \pm 4.60$ & $24.85 \pm 7.57$ & $0.0 \pm 3.43$ \\
\hline 6 & 34 & $5.66 \pm 4.53$ & $18.58 \pm 7.33$ & $0.0 \pm 1.71$ \\
\hline 8 & 46 & $6.25 \pm 4.66$ & $28.35 \pm 8.27$ & $0.0 \pm 3.01$ \\
\hline 9 & 41 & $8.55 \pm 5.22$ & $22.33 \pm 7.50$ & $0.0 \pm 3.76$ \\
\hline 10 & 46 & $6.22 \pm 4.67$ & $20.20 \pm 6.92$ & $0.0 \pm 0.35$ \\
\hline 11 & 45 & $9.12 \pm 5.84$ & $61.41 \pm 13.92$ & $0.0 \pm 0.26$ \\
\hline 12 & 45 & $11.13 \pm 5.88$ & $89.20 \pm 13.81$ & $0.0 \pm 2.08$ \\
\hline
\end{tabular}

Minimum Detectable Limit $=1 \times 10^{-16} \mathrm{\mu Ci} / \mathrm{ml}$

Reported errors are at the $95 \%$ confidence level

Table VII. Summary of Gross Beta Activity in Air for 1977

\begin{tabular}{|c|c|c|c|c|}
\hline $\begin{array}{l}\text { Sample } \\
\text { Station }\end{array}$ & $\begin{array}{l}\text { Number } \\
\text { Samples }\end{array}$ & $\begin{array}{c}\text { Average } \mu \mathrm{Ci} / \mathrm{m \ell} \\
\left(10^{-15}\right)\end{array}$ & $\begin{array}{l}\text { Maximum } \mu \mathrm{Ci} / \mathrm{m} \ell \\
\left(10^{-15}\right)\end{array}$ & $\begin{array}{l}\text { Minimum } \mu \mathrm{Ci} / \mathrm{m} \ell \\
\left(10^{-15}\right)\end{array}$ \\
\hline 1 & 23 & $59.70 \pm 3.42$ & $315.88 \pm 7.52$ & $3.50 \pm 1.28$ \\
\hline 2 & 27 & $49.80 \pm 3.15$ & $281.05 \pm 7.10$ & $1.02 \pm 1.13$ \\
\hline 3 & 47 & $57.40 \pm 3.50$ & $436.27 \pm 9.45$ & $0.0 \pm 0.93$ \\
\hline 4 & 24 & $51.40 \pm 3.34$ & $204.20 \pm 6.52$ & $0.01 \pm 0.85$ \\
\hline 5 & 47 & $56.46 \pm 3.45$ & $486.28 \pm 9.97$ & $0.0 \pm 0.92$ \\
\hline 6 & 34 & $70.50 \pm 3.91$ & $432.05 \pm 9.41$ & $0.0 \pm 0.47$ \\
\hline 8 & 46 & $66.63 \pm 3.70$ & $389.39 \pm 8.93$ & $0.29 \pm 0.89$ \\
\hline 9 & 41 & $61.52 \pm 3.57$ & $343.98 \pm 8.41$ & $0.0 \pm 0.88$ \\
\hline 10 & 46 & $46.25 \pm 3.16$ & $242.05 \pm 7.08$ & $0.0 \pm 0.69$ \\
\hline 11 & 44 & $52.13 \pm 3.35$ & $511.21 \pm 8.55$ & $0.0 \pm 1.11$ \\
\hline 12 & 45 & $49.02 \pm 3.34$ & $351.29 \pm 9.20$ & $0.0 \pm 0.45$ \\
\hline
\end{tabular}

Minimum Detectable Limit $=1 \times 10^{-15} \mu \mathrm{Ci} / \mathrm{ml}$

Reported errors are at the $95 \%$ confidence level 
Table VIII. Summary of Uranium in Air for 1977

\begin{tabular}{|c|c|c|c|c|c|}
\hline $\begin{array}{l}\text { Sample } \\
\text { Station } \\
\end{array}$ & $\begin{array}{l}\text { Number } \\
\text { Samples } \\
\end{array}$ & $\begin{array}{l}\text { Average } \mu \mathrm{Ci} / \mathrm{m} \ell \\
\left(10^{-16}\right)\end{array}$ & $\begin{array}{c}\text { Maximum } \mu \mathrm{Ci} / \mathrm{m} \ell \\
\left(10^{-16}\right) \\
\end{array}$ & $\begin{array}{c}\operatorname{Minimm} \mu \mathrm{Ci} / \mathrm{m} \ell \\
\left(10^{-16}\right) \\
\end{array}$ & $\begin{array}{r}\% \text { RCG } \\
\text { Average } \\
\end{array}$ \\
\hline 1 & 6 & $4.15 \pm 5.67$ & $5.88 \pm 3.68$ & $1.00 \pm 4.82$ & 0.04 \\
\hline 2 & 8 & $9.72 \pm 7.87$ & $24.63 \pm 6.07$ & $0.60 \pm 4.82$ & 0.10 \\
\hline 3 & 9 & $5.13 \pm 4.73$ & $7.49 \pm 4.79$ & $1.93 \pm 2.99$ & 0.05 \\
\hline 4 & 3 & $8.21 \pm 4.57$ & $19.57 \pm 6.45$ & $0.70 \pm 2.81$ & 0.08 \\
\hline 5 & 9 & $8.77 \pm 6.02$ & $40.39 \pm 8.74$ & $2.50 \pm 3.00$ & 0.09 \\
\hline 6 & 9 & $14.42 \pm 6.34$ & $52.15 \pm 7.65$ & $3.41 \pm 6.02$ & 0.14 \\
\hline 8 & 9 & $5.90 \pm 5.18$ & $17.41 \pm 9.61$ & $1.00 \pm 4.82$ & 0.06 \\
\hline 9 & 8 & $4.52 \pm 5.07$ & $9.23 \pm 6.83$ & $2.21 \pm 5.02$ & 0.05 \\
\hline 10 & 9 & $8.52 \pm 6.61$ & $21.22 \pm 9.97$ & $3.81 \pm 5.42$ & 0.09 \\
\hline 11 & 9 & $10.73 \pm 8.49$ & $18.85 \pm 12.78$ & $3.83 \pm 2.56$ & 0.11 \\
\hline 12 & 9 & $10.59 \pm 8.02$ & $18.74 \pm 7.31$ & $2.17 \pm 2.30$ & 0.10 \\
\hline
\end{tabular}

Minimum Detectable Limit $=2 \times 10^{-16} \mu \mathrm{Ci} / \mathrm{ml}$

Radioactivity Concentration Guide $=1 \times 10^{-12} \mu \mathrm{Ci} / \mathrm{ml}$

Reported errors are counting errors at the $95 \%$ confidence level 
Table IX. Summary of Plutonium 239 in Air for 1977

\begin{tabular}{|c|c|c|c|c|c|}
\hline $\begin{array}{l}\text { Sample } \\
\text { Station }\end{array}$ & $\begin{array}{l}\text { Number } \\
\text { Samples }\end{array}$ & $\begin{array}{c}\text { Average } \mu \mathrm{Ci} / \mathrm{m} \ell \\
\left(10^{-17}\right)\end{array}$ & $\begin{array}{c}\text { Maximum } \mu \mathrm{Ci} / \mathrm{m \ell} \\
\quad\left(10^{-17}\right) \\
\end{array}$ & $\begin{array}{c}\text { Minimum } \mu \mathrm{Ci} / \mathrm{m} \ell \\
\left(10^{-17}\right)\end{array}$ & $\begin{array}{r}\because \mathrm{RCG} \\
\text { Average } \\
\end{array}$ \\
\hline 1 & 6 & $0.0 \pm 0.91$ & $0.0 \pm 0.83$ & $0.0 \pm 0.83$ & 0.0 \\
\hline 2 & 8 & $0.0 \pm 1.73$ & $0.0 \pm 0.83$ & $0.0 \pm 0.83$ & 0.0 \\
\hline 3 & 9 & $0.0 \pm 0.93$ & $0.0 \pm 0.83$ & $0.0 \pm 0.83$ & 0.0 \\
\hline 4 & 3 & $0.42 \pm 1.21$ & $1.25 \pm 1.67$ & $0.0 \pm 0.88$ & 0.0 \\
\hline 5 & 9 & $0.09 \pm 0.98$ & $0.83 \pm 1.46$ & $0.0 \pm 0.83$ & 0.0 \\
\hline 6 & 9 & $3.57 \pm 8.91$ & $29.67 \pm 26.55$ & $0.0 \pm 1.00$ & 0.0 \\
\hline 8 & 9 & $0.0 \pm 0.93$ & $0.0 \pm 0.78$ & $0.0 \pm 0.78$ & 0.0 \\
\hline 9 & 8 & $0.16 \pm 0.99$ & $1.27 \pm 1.27$ & $0.0 \pm 1.00$ & 0.0 \\
\hline 10 & 9 & $0.0 \pm 0.93$ & $0.0 \pm 0.78$ & $0.0 \pm 0.78$ & 0.0 \\
\hline 11 & 9 & $0.0 \pm 1.57$ & $0.0 \pm 0.64$ & $0.0 \pm 0.64$ & 0.0 \\
\hline 12 & 9 & $0.0 \pm 1.26$ & $0.0 \pm 0.64$ & $0.0 \pm 0.64$ & 0.0 \\
\hline
\end{tabular}

Minimum Detectable Limit $=1 \times 10^{-17} \mu \mathrm{Ci} / \mathrm{ml}$

Radioactivity Concentration Guide $=2 \times 10^{-14} \mu \mathrm{Ci} / \mathrm{ml}$

Reported errors are counting errors at the $95 \%$ confidence level 
Table X. Summary of Tritium Oxide in Air for 1977

\begin{tabular}{|c|c|c|c|c|c|}
\hline $\begin{array}{l}\text { Sample } \\
\text { Station } \\
\end{array}$ & $\begin{array}{l}\text { Number } \\
\text { Samp1es } \\
\end{array}$ & $\begin{array}{l}\text { Average } \mu \mathrm{Ci} / \mathrm{m} \ell \\
\quad\left(10^{-12}\right) \\
\end{array}$ & $\begin{array}{c}\operatorname{Maximm} \mu \mathrm{Ci} / \mathrm{m} \ell \\
\quad\left(10^{-12}\right) \\
\end{array}$ & $\begin{array}{l}\text { Minimum } \mu \mathrm{Ci} / \mathrm{m} \ell \\
\left(10^{-12}\right) \\
\end{array}$ & $\begin{array}{r}: \text { RCG } \\
\text { Average } \\
\end{array}$ \\
\hline 1 & 23 & $0.0 \pm 0.11$ & $0.0 \pm 0.99$ & $0.0 \pm 0.99$ & 0.0 \\
\hline 2 & 28 & $0.0 \pm 0.10$ & $0.0 \pm 0.99$ & $0.0 \pm 0.99$ & 0.0 \\
\hline 3 & 43 & $0.0 \pm 0.08$ & $0.0 \pm 0.99$ & $0.0 \pm 0.99$ & 0.0 \\
\hline 4 & 21 & $0.0 \pm 0.08$ & $0.0 \pm 0.99$ & $0.0 \pm 0.99$ & 0.0 \\
\hline 5 & 43 & $0.0 \pm 0.08$ & $0.0 \pm 0.99$ & $0.0 \pm 0.99$ & 0.0 \\
\hline 6 & 43 & $0.0 \pm 0.08$ & $0.0 \pm 0.99$ & $0.0 \pm 0.99$ & 0.0 \\
\hline 8 & 43 & $0.0 \pm 0.06$ & $0.0 \pm 0.99$ & $0.0 \pm 0.99$ & 0.0 \\
\hline 9 & 38 & $0.0 \pm 0.07$ & $0.0 \pm 0.99$ & $0.0 \pm 0.99$ & 0.0 \\
\hline 10 & 42 & $0.0 \pm 0.01$ & $0.0 \pm 0.99$ & $0.0 \pm 0.99$ & 0.0 \\
\hline 11 & 32 & $0.0 \pm 0.05$ & $0.0 \pm 0.99$ & $0.0 \pm 0.99$ & 0.0 \\
\hline 12 & 37 & $0.0 \pm 0.11$ & $0.0 \pm 0.99$ & $0.0 \pm 0.99$ & 0.0 \\
\hline
\end{tabular}

Minimum Detectable Limit $=1 \times 10^{-12} \mu \mathrm{Ci} / \mathrm{ml}$

Radioactivity Concentration Guide $=2 \times 10^{-7} \mu \mathrm{Ci} / \mathrm{ml}$

Reported errors are at $95 \%$ confidence level 
Table XI. Summary of Dissolved Alpha Activity in Water for 1977

\begin{tabular}{|c|c|c|c|c|}
\hline $\begin{array}{l}\text { Sample } \\
\text { Station } \\
\end{array}$ & $\begin{array}{l}\text { Number } \\
\text { Samples } \\
\end{array}$ & $\begin{array}{l}\text { Average } \mu \mathrm{Ci} / \mathrm{m} \ell \\
\left(10^{-9}\right) \\
\end{array}$ & $\begin{array}{l}\text { Maximum } \mu \mathrm{Ci} / \mathrm{m} \ell \\
\left(10^{-9}\right)\end{array}$ & $\begin{array}{l}\text { Minimum } \mu \mathrm{Ci} / \mathrm{me} \\
\left(10^{-9}\right)\end{array}$ \\
\hline 1 & 3 & $6.37 \pm 3.54$ & $11.30 \pm 2.50$ & $0.0 \pm 5.00$ \\
\hline 2 & 2 & $22.80 \pm 5.45$ & $33.60 \pm 4.70$ & $12.00 \pm 6.10$ \\
\hline 6 & 10 & $5.86 \pm 3.68$ & $12.50 \pm 4.40$ & $0.0 \pm 5.00$ \\
\hline 7 & 7 & $8.19 \pm 4.08$ & $26.10 \pm 5.30$ & $0.0 \pm 5.00$ \\
\hline 8 & 10 & $6.32 \pm 4.77$ & $21.30 \pm 5.10$ & $0.0 \pm 5.00$ \\
\hline 19 & 10 & $0.41 \pm 4.79$ & $4.10 \pm 2.00$ & $0.0 \pm 5.00$ \\
\hline 20 & 9 & $1.32 \pm 4.82$ & $6.60 \pm 5.10$ & $0.0 \pm 5.00$ \\
\hline
\end{tabular}

Minimum Detectable Limit $=5 \times 10^{-9} \mu \mathrm{Ci} / \mathrm{ml}$

Reported errors are counting errors at $95 \%$ confidence level

Table XII. Summary of Suspended Alpha Activity in Water for 1977

\begin{tabular}{|c|c|c|c|c|}
\hline $\begin{array}{l}\text { Sample } \\
\text { Station }\end{array}$ & $\begin{array}{l}\text { Number } \\
\text { Samples } \\
\end{array}$ & $\begin{array}{l}\text { Average } \mu \mathrm{Ci} / \mathrm{m} \ell \\
\left(10^{-9}\right)\end{array}$ & $\begin{array}{l}\text { Maximum } \mu \mathrm{Ci} / \mathrm{m \ell} \\
\left(10^{-9}\right) \\
\end{array}$ & $\begin{array}{l}\text { Minimm } \mu \mathrm{Ci} / \mathrm{m \ell} \\
\left(10^{-9}\right)\end{array}$ \\
\hline 1 & 3 & $0.0 \pm 4.24$ & $0.0 \pm 5.00$ & $0.0 \pm 5.00$ \\
\hline 2 & 2 & $11.10 \pm 4.02$ & $22.20 \pm 2.70$ & $0.0 \pm 5.00$ \\
\hline 6 & 9 & $3.47 \pm 4.21$ & $15.80 \pm 4.60$ & $0.0 \pm 5.00$ \\
\hline 7 & 7 & $1.34 \pm 4.54$ & $9.40 \pm 3.90$ & $0.0 \pm 5.00$ \\
\hline 8 & 9 & $3.52 \pm 4.02$ & $16.20 \pm 2.30$ & $0.0 \pm 5.00$ \\
\hline 19 & 9 & $4.76 \pm 4.66$ & $13.50 \pm 9.70$ & $0.0 \pm 5.00$ \\
\hline 20 & 8 & $2.59 \pm 4.09$ & $7.20 \pm 4.50$ & $0.0 \pm 5.00$ \\
\hline
\end{tabular}

Minimum Detectable Limit $=5 \times 10^{-9} \mu \mathrm{Ci} / \mathrm{ml}$

Reported errors are counting errors at $95 \%$ confidence level 
Table XIII. Summary of Dissolved Beta Activity in Water for 1977

\begin{tabular}{|c|c|c|c|c|}
\hline $\begin{array}{l}\text { Sample } \\
\text { Station }\end{array}$ & $\begin{array}{l}\text { Number } \\
\text { Samples } \\
\end{array}$ & $\begin{array}{l}\text { Average } \mu \mathrm{Ci} / \mathrm{m} \ell \\
\left(10^{-9}\right)\end{array}$ & $\begin{array}{c}\operatorname{Maximum} \mu \mathrm{Ci} / \mathrm{m} \ell \\
\left(10^{-9}\right)\end{array}$ & $\begin{array}{c}\operatorname{Minimm} \mu \mathrm{Ci} / \mathrm{m} \ell \\
\left(10^{-9}\right)\end{array}$ \\
\hline 1 & 3 & $10.23 \pm 1.91$ & $15.60 \pm 1.90$ & $3.20 \pm 2.10$ \\
\hline 2 & 2 & $10.55 \pm 2.75$ & $10.90 \pm 1.70$ & $10.20 \pm 3.50$ \\
\hline 6 & 10 & $5.74 \pm 2.03$ & $8.20 \pm 2.00$ & $4.30 \pm 1.60$ \\
\hline 7 & 7 & $6.33 \pm 2.09$ & $9.70 \pm 2.00$ & $3.40 \pm 1.30$ \\
\hline 8 & 10 & $9.93 \pm 2.09$ & $14.70 \pm 1.90$ & $6.20 \pm 2.20$ \\
\hline 19 & 10 & $2.81 \pm 1.77$ & $6.80 \pm 2.20$ & $0.0 \pm 2.00$ \\
\hline 20 & 9 & $5.06 \pm 1.89$ & $6.70 \pm 1.90$ & $4.20 \pm 1.80$ \\
\hline
\end{tabular}

Minimum Detectable Limit $=2 \times 10^{-9} \mu \mathrm{Ci} / \mathrm{ml}$

Reported errors are counting errors at $95 \%$ confidence level

Table XIV. Summary of Suspended Beta Activity in Water for 1977

\begin{tabular}{|c|c|c|c|c|}
\hline $\begin{array}{l}\text { Sample } \\
\text { Station }\end{array}$ & $\begin{array}{l}\text { Number } \\
\text { Samples }\end{array}$ & $\begin{array}{l}\text { Average } \mu \mathrm{Ci} / \mathrm{m} \ell \\
\left(10^{-9}\right)\end{array}$ & $\begin{array}{c}\text { Maximm } \mu \mathrm{C} i / \mathrm{m} \ell \\
\left(10^{-9}\right)\end{array}$ & $\underset{(10-9)}{\operatorname{Minimm}} \mu \mathrm{Ci} / \mathrm{ml}$ \\
\hline 1 & 3 & $2.17 \pm 1.85$ & $6.50 \pm 1.50$ & $0.0 \pm 2.00$ \\
\hline 2 & 2 & $3.65 \pm 1.81$ & $7.30 \pm 1.60$ & $0.0 \pm 2.00$ \\
\hline 6 & 9 & $3.02 \pm 1.91$ & $14.60 \pm 2.10$ & $0.0 \pm 2.00$ \\
\hline 7 & 7 & $1.00 \pm 2.15$ & $5.00 \pm 3.20$ & $0.0 \pm 2.00$ \\
\hline 8 & 9 & $1.49 \pm 1.90$ & $5.60 \pm 1.60$ & $0.0 \pm 2.00$ \\
\hline 19 & 9 & $1.44 \pm 2.13$ & $4.70 \pm 3.20$ & $0.0 \pm 2.00$ \\
\hline 20 & 8 & $1.96 \pm 1.95$ & $5.00 \pm 1.60$ & $0.0 \pm 2.00$ \\
\hline
\end{tabular}

Minimum Detectable Limit $=2 \times 10^{-9} \mu \mathrm{Ci} / \mathrm{ml}$

Reported errors are counting errors at $95 \%$ confidence level 
Table XV. Summary of Tota1 Uranium in Water for 1977

\begin{tabular}{|c|c|c|c|c|}
\hline $\begin{array}{l}\text { Sample } \\
\text { Station } \\
\end{array}$ & $\begin{array}{l}\text { Number } \\
\text { Samples } \\
\end{array}$ & $\begin{array}{l}\text { Average } \mu \mathrm{Ci} / \mathrm{m} \ell \\
\left(10^{-9}\right) \\
\end{array}$ & $\begin{array}{l}\text { Maximum } \mu \mathrm{Ci} / \mathrm{m \ell} \\
\left(10^{-9}\right) \\
\end{array}$ & $\begin{array}{c}\text { Minimum } \mu \mathrm{Ci} / \mathrm{m} \ell \\
\left(10^{-9}\right)\end{array}$ \\
\hline 1 & 3 & $6.17 \pm 3.77$ & $12.20 \pm 4.70$ & $2.40 \pm 3.00$ \\
\hline 2 & 2 & $6.60 \pm 3.34$ & $8.50 \pm 4.00$ & $4.70 \pm 2.50$ \\
\hline 6 & 10 & $6.60 \pm 3.75$ & $12.20 \pm 4.70$ & $2.40 \pm 3.00$ \\
\hline 7 & 7 & $7.67 \pm 3.97$ & $15.20 \pm 5.00$ & $5.30 \pm 3.50$ \\
\hline 8 & 10 & $7.80 \pm 4.00$ & $13.50 \pm 4.80$ & $3.20 \pm 3.40$ \\
\hline 19 & 10 & $3.24 \pm 3.19$ & $9.00 \pm 4.30$ & $0.60 \pm 2.30$ \\
\hline 20 & 9 & $6.44 \pm 3.77$ & $10.10 \pm 4.30$ & $0.90 \pm 2.70$ \\
\hline
\end{tabular}

Minimum Detectable Limit $=5 \times 10^{-10} \mu \mathrm{Ci} / \mathrm{ml}\left(\begin{array}{ll}1.5 \mu \mathrm{g} & \mathrm{U} / \mathrm{l}\end{array}\right)$

Radioactivity Concentration Guide $=1 \times 10^{-5} \mu \mathrm{Ci} / \mathrm{ml}$

Reported errors are counting errors at $95 \%$ confidence level 
Table XVI. Summary of Plutonium 239 in Water for 1977

\begin{tabular}{|c|c|c|c|c|c|c|}
\hline $\begin{array}{l}\text { Sample } \\
\text { Station }\end{array}$ & $\begin{array}{l}\text { Number } \\
\text { Samples } \\
\end{array}$ & $\begin{array}{r}\text { Average } \\
\quad(10 \\
\end{array}$ & $\begin{array}{l}\mu \mathrm{Ci} / \mathrm{m} \ell \\
-10)\end{array}$ & $\begin{array}{c}\text { Maximm } \mu \mathrm{Ci} / \mathrm{m} \ell \\
\left(10^{-10}\right) \\
\end{array}$ & $\begin{array}{c}\text { Minimum } \mu \mathrm{Ci} / \mathrm{m} \ell \\
\left(10^{-10}\right)\end{array}$ & $\begin{array}{c}\% \text { RCG } \\
\text { Average } \\
\end{array}$ \\
\hline 1 & 3 & 0.0 & \pm 0.42 & $0.0 \pm 0.20$ & $0.0 \pm 0.20$ & 0.0 \\
\hline 2 & 3 & 0.0 & \pm 0.31 & $0.0 \pm 0.20$ & $0.0 \pm 0.20$ & 0.0 \\
\hline 6 & 11 & 0.0 & \pm 0.33 & $0.0 \pm 0.20$ & $0.0 \pm 0.20$ & 0.0 \\
\hline 7 & 8 & 0.0 & \pm 0.33 & $0.0 \pm 0.20$ & $0.0 \pm 0.20$ & 0.0 \\
\hline 8 & 11 & 0.0 & \pm 0.38 & $0.0 \pm 0.20$ & $0.0 \pm 0.20$ & 0.0 \\
\hline 19 & 11 & 0.0 & \pm 0.38 & $0.0 \pm 0.20$ & $0.0 \pm 0.20$ & 0.0 \\
\hline 20 & 10 & 0.0 & \pm 0.40 & $0.0 \pm 0.20$ & $0.0 \pm 0.20$ & 0.0 \\
\hline
\end{tabular}

Minimum Detectable Limit $=2 \times 10^{-11} \mu \mathrm{Ci} / \mathrm{ml}$

Radioactivity Concentration Guide $(R C G)=2 \times 10^{-6} \mu \mathrm{Ci} / \mathrm{ml}$

Errors are reported at the $95 \%$ confidence level

Table XVII. Summary of Tritium Oxide in Water for 1977

\begin{tabular}{|c|c|c|c|c|c|}
\hline $\begin{array}{l}\text { Sample } \\
\text { Station }\end{array}$ & $\begin{array}{l}\text { Number } \\
\text { Samples } \\
\end{array}$ & $\begin{array}{l}\text { Average } \mu \mathrm{Ci} / \mathrm{m} \ell \\
\left(10^{-6}\right)\end{array}$ & $\begin{array}{l}\text { Maximm } \mu \mathrm{Ci} / \mathrm{ml} \\
\left(10^{-6}\right) \\
\end{array}$ & $\begin{array}{l}\text { Minimum } \mu \mathrm{Ci} / \mathrm{m} \ell \\
\left(10^{-6}\right) \\
\end{array}$ & $\begin{array}{r}\% \text { RCG } \\
\text { Average } \\
\end{array}$ \\
\hline 1 & 3 & $0.0 \pm 0.41$ & $0.0 \pm 0.50$ & $0.0 \pm 0.50$ & 0.0 \\
\hline 2 & 2 & $0.0 \pm 0.50$ & $0.0 \pm 0.50$ & $0.0 \pm 0.50$ & 0.0 \\
\hline 6 & 10 & $0.0 \pm 0.42$ & $0.0 \pm 0.50$ & $0.0 \pm 0.50$ & 0.0 \\
\hline 7 & 7 & $0.0 \pm 0.42$ & $0.0 \pm 0.50$ & $0.0 \pm 0.50$ & 0.0 \\
\hline 8 & 10 & $0.0 \pm 0.42$ & $0.0 \pm 0.50$ & $0.0 \pm 0.50$ & 0.0 \\
\hline 19 & 10 & $0.0 \pm 0.42$ & $0.0 \pm 0.50$ & $0.0 \pm 0.50$ & 0.0 \\
\hline 20 & 9 & $0.0 \pm 0.41$ & $0.0 \pm 0.50$ & $0.0 \pm 0.50$ & 0.0 \\
\hline
\end{tabular}

Minimum Detectable Limit $=5 \times 10^{-7} \mathrm{\mu Ci} / \mathrm{ml}$

Radioactivity Concentration Guide $(R C G)=1 \times 10^{-3} \mu \mathrm{Ci} / \mathrm{ml}$

Errors are reported at the $95 \%$ confidence level 
Table XVIII. Summary of Total Uranium in Soil for 1977

\begin{tabular}{|c|c|c|c|c|}
\hline $\begin{array}{l}\text { Sample } \\
\text { Station }\end{array}$ & $\begin{array}{l}\text { Number } \\
\text { Samples }\end{array}$ & $\begin{array}{l}\text { Average } \mu \mathrm{Ci} / \mathrm{g} \\
\quad\left(10^{-}-7\right) \\
\end{array}$ & $\begin{array}{c}\text { Maximum } \mu \mathrm{Ci} / \mathrm{g} \\
\left(10^{-7}\right)\end{array}$ & $\begin{array}{c}\text { Minimum } \mu \mathrm{Ci} / \mathrm{g} \\
\left(10^{-7}\right)\end{array}$ \\
\hline SS- 01 & 9 & $3.47 \pm 0.69$ & $5.06 \pm 0.83$ & $2.14 \pm 0.59$ \\
\hline SS- 02 & 9 & $4.08 \pm 0.75$ & $10.20 \pm 1.20$ & $1.25 \pm 0.49$ \\
\hline SS- 03 & 9 & $3.40 \pm 0.68$ & $6.38 \pm 0.86$ & $1.81 \pm 0.56$ \\
\hline SS-04 & 9 & $3.69 \pm 0.69$ & $11.80 \pm 1.10$ & $0.45 \pm 0.39$ \\
\hline SS- 05 & 9 & $4.09 \pm 0.73$ & $6.35 \pm 0.86$ & $1.99 \pm 0.57$ \\
\hline SS-06 & 9 & $5.22 \pm 0.82$ & $20.10 \pm 1.60$ & $1.96 \pm 0.57$ \\
\hline SS- 07 & 9 & $3.22 \pm 0.66$ & $5.80 \pm 0.83$ & $1.84 \pm 0.52$ \\
\hline SS- 08 & 9 & $4.57 \pm 0.77$ & $8.52 \pm 1.08$ & $1.51 \pm 0.43$ \\
\hline SS-09 & 9 & $4.11 \pm 0.73$ & $8.23 \pm 0.96$ & $1.25 \pm 0.49$ \\
\hline SS- 10 & 9 & $3.07 \pm 0.64$ & $7.12 \pm 0.90$ & $0.48 \pm 0.29$ \\
\hline SS- 11 & 9 & $3.94 \pm 0.71$ & $7.96 \pm 0.95$ & $1.78 \pm 0.51$ \\
\hline SS- 12 & 9 & $3.71 \pm 0.70$ & $10.10 \pm 1.10$ & $0.59 \pm 0.41$ \\
\hline SS- 13 & 9 & $4.08 \pm 0.73$ & $10.00 \pm 1.10$ & $1.25 \pm 0.49$ \\
\hline SS- 14 & 9 & $3.30 \pm 0.66$ & $7.76 \pm 0.94$ & $0.92 \pm 0.45$ \\
\hline SS-15 & 9 & $3.86 \pm 0.70$ & $9.77 \pm 1.04$ & $1.75 \pm 0.55$ \\
\hline SS- 16 & 9 & $4.15 \pm 0.73$ & $8.34 \pm 0.97$ & $1.79 \pm 0.54$ \\
\hline SS- 17 & 9 & $4.09 \pm 0.74$ & $7.33 \pm 0.91$ & $2.14 \pm 0.59$ \\
\hline SS- 18 & 9 & $3.83 \pm 0.72$ & $9.13 \pm 1.01$ & $2.08 \pm 0.50$ \\
\hline SS- 19 & 9 & $3.86 \pm 0.71$ & $9.29 \pm 1.02$ & $2.06 \pm 0.50$ \\
\hline SS- 20 & 9 & $5.31 \pm 0.82$ & $17.30 \pm 1.50$ & $1.75 \pm 0.51$ \\
\hline SS- 21 & 9 & $3.48 \pm 0.67$ & $8.89 \pm 1.00$ & $1.00 \pm 0.37$ \\
\hline SS- 22 & 9 & $4.85 \pm 0.78$ & $10.10 \pm 1.06$ & $2.88 \pm 0.62$ \\
\hline SS- 23 & 9 & $3.58 \pm 0.68$ & $9.29 \pm 1.02$ & $2.17 \pm 0.56$ \\
\hline SS- 24 & 9 & $3.82 \pm 0.70$ & $8.55 \pm 0.98$ & $1.48 \pm 0.52$ \\
\hline$S S-25$ & 9 & $3.81 \pm 0.69$ & $6.54 \pm 0.87$ & $2.39 \pm 0.40$ \\
\hline SS- 26 & 9 & $3.96 \pm 0.71$ & $6.91 \pm 0.89$ & $2.32 \pm 0.58$ \\
\hline SS -27 & 9 & $6.37 \pm 0.91$ & $17.90 \pm 1.50$ & $2.81 \pm 0.56$ \\
\hline SS- 28 & 9 & $3.57 \pm 0.68$ & $6.35 \pm 0.86$ & $2.38 \pm 0.53$ \\
\hline SS- 29 & 9 & $4.76 \pm 0.77$ & $9.32 \pm 1.06$ & $1.67 \pm 0.52$ \\
\hline SS- 30 & 9 & $5.13 \pm 0.79$ & $11.40 \pm 1.12$ & $0.83 \pm 0.41$ \\
\hline SS- 31 & 9 & $4.26 \pm 0.74$ & $6.66 \pm 0.96$ & $2.55 \pm 0.59$ \\
\hline
\end{tabular}

Minimum Detectable Limit $=1 \times 10^{-8} \mu \mathrm{Ci} / \mathrm{g}$ Reported errors are at the $95 \%$ confidence level Activity is per gram of dry soil 
Table XIX. Summary of Plutonium 239 in Soil for 1977

\begin{tabular}{|c|c|c|c|c|}
\hline $\begin{array}{l}\text { Sample } \\
\text { Station }\end{array}$ & $\begin{array}{l}\text { Number } \\
\text { Samples } \\
\end{array}$ & $\begin{array}{l}\text { Average }{ }_{\mu} \mu \mathrm{Ci} / \mathrm{g} \\
\quad\left(10^{-6}\right)\end{array}$ & $\begin{array}{c}\text { Maximum } \mu \mathrm{Ci} / \mathrm{g} \\
\left(10^{-6}\right)\end{array}$ & $\begin{array}{c}\text { Minimum } \mu \mathrm{Ci} / \mathrm{g} \\
\left(10^{-6}\right)\end{array}$ \\
\hline SS-01 & 10 & $0.0 \pm 0.02$ & $0.0 \pm 0.02$ & $0.0 \pm 0.02$ \\
\hline SS-02 & 10 & $0.00 \pm 0.02$ & $0.02 \pm 0.02$ & $0.0 \pm 0.02$ \\
\hline SS- 03 & 10 & $0.0 \pm 0.02$ & $0.0 \pm 0.02$ & $0.0 \pm 0.02$ \\
\hline SS- 04 & 10 & $0.00 \pm 0.02$ & $0.03 \pm 0.01$ & $0.0 \pm 0.02$ \\
\hline SS- 05 & 10 & $0.0 \pm 0.02$ & $0.0 \pm 0.02$ & $0.0 \pm 0.02$ \\
\hline SS-06 & 10 & $0.00 \pm 0.02$ & $0.05 \pm 0.04$ & $0.0 \pm 0.02$ \\
\hline SS- 07 & 10 & $0.0 \pm 0.02$ & $0.0 \pm 0.02$ & $0.0 \pm 0.02$ \\
\hline SS-08 & 10 & $0.0 \pm 0.02$ & $0.0 \pm 0.02$ & $0.0 \pm 0.02$ \\
\hline SS- 09 & 10 & $0.0 \pm 0.02$ & $0.0 \pm 0.02$ & $0.0 \pm 0.02$ \\
\hline SS- 10 & 10 & $0.0 \pm 0.02$ & $0.0 \pm 0.02$ & $0.0 \pm 0.02$ \\
\hline SS- 11 & 10 & $0.0 \pm 0.02$ & $0.0 \pm 0.02$ & $0.0 \pm 0.02$ \\
\hline SS-12 & 10 & $0.0 \pm 0.02$ & $0.0 \pm 0.02$ & $0.0 \pm 0.02$ \\
\hline SS-13 & 10 & $0.0 \pm 0.02$ & $0.0 \pm 0.02$ & $0.0 \pm 0.02$ \\
\hline SS-14 & 10 & $0.0 \pm 0.02$ & $0.0 \pm 0.02$ & $0.0 \pm 0.02$ \\
\hline SS-15 & 10 & $0.0 \pm 0.02$ & $0.0 \pm 0.02$ & $0.0 \pm 0.02$ \\
\hline SS-16 & 10 & $0.00 \pm 0.02$ & $0.03 \pm 0.03$ & $0.0 \pm 0.02$ \\
\hline SS-17 & 10 & $0.0 \pm 0.02$ & $0.0 \pm 0.02$ & $0.0 \pm 0.02$ \\
\hline SS-18 & 10 & $0.0 \pm 0.02$ & $0.0 \pm 0.02$ & $0.0 \pm 0.02$ \\
\hline SS- 19 & 10 & $0.0 \pm 0.02$ & $0.0 \pm 0.02$ & $0.0 \pm 0.02$ \\
\hline SS- 20 & 10 & $0.0 \pm 0.02$ & $0.0 \pm 0.02$ & $0.0 \pm 0.02$ \\
\hline SS-21 & 10 & $0.0 \pm 0.02$ & $0.0 \pm 0.02$ & $0.0 \pm 0.02$ \\
\hline SS-22 & 10 & $0.0 \pm 0.02$ & $0.0 \pm 0.02$ & $0.0 \pm 0.02$ \\
\hline SS-23 & 10 & $0.0 \pm 0.02$ & $0.0 \pm 0.02$ & $0.0 \pm 0.02$ \\
\hline SS-24 & 10 & $0.0 \pm 0.02$ & $0.0 \pm 0.02$ & $0.0 \pm 0.02$ \\
\hline SS- 25 & 10 & $0.01 \pm 0.02$ & $0.06 \pm 0.04$ & $0.0 \pm 0.02$ \\
\hline SS- 26 & 10 & $0.00 \pm 0.02$ & $0.03 \pm 0.01$ & $0.0 \pm 0.02$ \\
\hline SS-27 & 10 & $0.0 \pm 0.02$ & $0.0 \pm 0.02$ & $0.0 \pm 0.02$ \\
\hline SS- 28 & 10 & $0.0 \pm 0.02$ & $0.0 \pm 0.02$ & $0.0 \pm 0.02$ \\
\hline SS-29 & 10 & $0.0 \pm 0.02$ & $0.0 \pm 0.02$ & $0.0 \pm 0.02$ \\
\hline SS -30 & 10 & $0.0 \pm 0.02$ & $0.0 \pm 0.02$ & $0.0 \pm 0.02$ \\
\hline SS-31 & 10 & $0.0 \pm 0.02$ & $0.0 \pm 0.02$ & $0.0 \pm 0.02$ \\
\hline
\end{tabular}

Minimum Detectable Limit $=2 \times 10^{-8} \mu \mathrm{Ci} / \mathrm{g}$ Revorted errors are at the $95 \%$ confidence levet Activity is per gram of dry soil 
Table XX. Summary of Tritium Oxide in Soil for 1977

Sample Number Average $\%$ Average $\mu \mathrm{Ci} / \mathrm{g}$ Maximum $\mu \mathrm{Ci} / \mathrm{g}$ Station Samples Moisture Moisture (10-6) Moisture $\left(10^{-6}\right)$

Minimum $\mu \mathrm{Ci} / \mathrm{g}$

SS- 01

11.3

$0.0 \pm 1.00$

$0.0 \pm 1.00$

Moisture $\left(10^{-6}\right)$

SS- 02

8.8

$0.0 \pm 1.00$

$0.0 \pm 1.00$

$0.0 \pm 1.00$

SS-03

7.9

$0.0 \pm 1.00$

$0.0 \pm 1.00$

$0.0 \pm 1.00$

SS- 04

6.9

$0.0 \pm 1.00$

$0.0 \pm 1.00$

$0.0 \pm 1.00$

SS-05

10.8

$0.0 \pm 1.00$

$0.0 \pm 1.00$

$0.0 \pm 1.00$

SS-06 2

12.1

$0.0 \pm 1.00$

$0.0 \pm 1.00$

$0.0 \pm 1.00$

SS-07 2

5.4

$0.0 \pm 1.00$

$0.0 \pm 1.00$

$0.0 \pm 1.00$

SS-08 2

7.0

$0.0 \pm 1.00$

$0.0 \pm 1.00$

$0.0 \pm 1.00$

SS-09 2

10.5

$0.0 \pm 1.00$

$0.0 \pm 1.00$

$0.0 \pm 1.00$

SS-10 2

10.0

$0.0 \pm 1.00$

$0.0 \pm 1.00$

$0.0 \pm 1.00$

SS- 11

11.0

$0.85 \pm 0.76$

$1.70 \pm 0.40$

$0.0 \pm 1.00$

SS- 12

6.6

$0.0 \pm 1.00$

$0.0 \pm 1.00$

$0.0 \pm 1.00$

SS- 13

9.2

$0.0 \pm 1.00$

$0.0 \pm 1.00$

$0.0 \pm 1.00$

SS-14

5.2

$0.0 \pm 1.00$

$0.0 \pm 1.00$

$0.0 \pm 1.00$

SS- 15

10.8

$0.0 \pm 1.00$

$0.0 \pm 1.00$

$0.0 \pm 1.00$

SS-16 2

9.0

$0.0 \pm 1.00$

$0.0 \pm 1.00$

$0.0 \pm 1.00$

SS-17 2

11.9

$0.0 \pm 1.00$

$0.0 \pm 1.00$

$0.0 \pm 1.00$

SS-18 2

10.0

$0.0 \pm 1.00$

$0.0 \pm 1.00$

$0.0 \pm 1.00$

SS-19 2

9.6

$0.0 \pm 1.00$

$0.0 \pm 1.00$

$0.0 \pm 1.00$

SS-20 2

5.0

$0.0 \pm 1.00$

$0.0 \pm 1.00$

$0.0 \pm 1.00$

SS-21

6.4

$0.0 \pm 1.00$

$0.0 \pm 1.00$

$0.0 \pm 1.00$

SS- $22 \quad 2$

4.3

$0.0 \pm 1.00$

$0.0 \pm 1.00$

$0.0 \pm 1.00$

SS-23 2

5.9

$0.0 \pm 1.00$

$0.0 \pm 1.00$

$0.0 \pm 1.00$

SS- $24 \quad 2$

6.0

$0.0 \pm 1.00$

$0.0 \pm 1.00$

$0.0 \pm 1.00$

SS- $25 \quad 2$

10.3

$0.0 \pm 1.00$

$0.0 \pm 1.00$

$0.0 \pm 1.00$

SS- $26 \quad 2$

6.8

$0.0 \pm 1.00$

$0.0 \pm 1.00$

$0.0 \pm 1.00$

SS- $27 \quad 2$

5.6

$0.0 \pm 1.00$

$0.0 \pm 1.00$

$0.0 \pm 1.00$

SS- 28

4.0

$0.0 \pm 1.00$

$0.0 \pm 1.00$

$0.0 \pm 1.00$

SS- 29

4.8

$0.0 \pm 1.00$

$0.0 \pm 1.00$

$0.0 \pm 1.00$

SS -30

5.8

$0.0 \pm 1.00$

$0.0 \pm 1.00$

$0.0 \pm 1.00$

SS-31

10.3

$0.0 \pm 1.00$

$0.0 \pm 1.00$

$0.0 \pm 1.00$

$0.0 \pm 1.00$

Minimum Detectable Limit $=1 \times 10^{-6} \mu \mathrm{Ci} / \mathrm{g}$ moisture Reported errors are at the $95 \%$ confidence level 
Table XXI. Summary of Tota1 Uranium in Vegetation for 1977

\begin{tabular}{|c|c|c|c|c|}
\hline $\begin{array}{l}\text { Sample } \\
\text { Station }\end{array}$ & $\begin{array}{l}\text { Number } \\
\text { Samples } \\
\end{array}$ & $\begin{array}{l}\text { Average } \mu \mathrm{Ci} / \mathrm{g} \\
\quad\left(10^{-7}\right) \\
\end{array}$ & $\begin{array}{c}\text { Maximum } \mu \mathrm{Ci} / \mathrm{g} \\
\left(10^{-7}\right)\end{array}$ & $\begin{array}{c}\text { Minimum } \mu \mathrm{Ci} / \mathrm{g} \\
\left(10^{-7}\right)\end{array}$ \\
\hline VS-01 & 10 & $2.31 \pm 0.58$ & $10.80 \pm 1.20$ & $0.40 \pm 0.30$ \\
\hline VS- 02 & 10 & $2.44 \pm 0.59$ & $6.00 \pm 0.90$ & $0.40 \pm 0.30$ \\
\hline VS- 03 & 10 & $4.47 \pm 0.78$ & $14.60 \pm 1.40$ & $0.20 \pm 0.30$ \\
\hline VS- 04 & 10 & $2.10 \pm 0.57$ & $9.30 \pm 1.10$ & $0.20 \pm 0.30$ \\
\hline VS-05 & 10 & $3.93 \pm 1.57$ & $18.30 \pm 4.70$ & $0.40 \pm 0.30$ \\
\hline VS-06 & 10 & $2.06 \pm 0.55$ & $3.40 \pm 0.70$ & $0.50 \pm 0.30$ \\
\hline VS-07 & 10 & $1.09 \pm 0.43$ & $2.40 \pm 0.60$ & $0.40 \pm 0.30$ \\
\hline VS-08 & 10 & $2.40 \pm 0.62$ & $8.30 \pm 1.00$ & $0.20 \pm 0.30$ \\
\hline VS-09 & 10 & $3.09 \pm 0.65$ & $9.30 \pm 1.10$ & $0.60 \pm 0.30$ \\
\hline VS-10 & 10 & $1.48 \pm 0.47$ & $4.30 \pm 0.60$ & $0.80 \pm 0.40$ \\
\hline VS-11 & 10 & $1.02 \pm 0.43$ & $2.20 \pm 0.60$ & $0.0 \pm 0.20$ \\
\hline VS-12 & 10 & $1.57 \pm 0.48$ & $2.40 \pm 0.40$ & $0.70 \pm 0.40$ \\
\hline VS-13 & 10 & $0.87 \pm 0.40$ & $1.70 \pm 0.50$ & $0.10 \pm 0.30$ \\
\hline VS-14 & 10 & $1.51 \pm 0.48$ & $3.30 \pm 0.70$ & $0.60 \pm 0.40$ \\
\hline VS-15 & 10 & $2.16 \pm 0.56$ & $5.90 \pm 0.90$ & $0.50 \pm 0.40$ \\
\hline VS-16 & 10 & $7.29 \pm 0.86$ & $33.60 \pm 1.50$ & $0.20 \pm 0.30$ \\
\hline
\end{tabular}

Minimum Detectable Limit $=2 \times 10^{-8} \mu / C i$

Reported errors are at the $95 \%$ confidence level

Results are per gram dry vegetation 
Table XXII. Summary of Tritium Oxide in Vegetation for 1977

\begin{tabular}{|c|c|c|c|c|c|}
\hline $\begin{array}{l}\text { Sample } \\
\text { Station } \\
\end{array}$ & $\begin{array}{l}\text { Number } \\
\text { Samples }\end{array}$ & $\begin{array}{l}\text { Average \% } \\
\text { Moisture } \\
\end{array}$ & $\begin{array}{r}\text { Average } \mu \mathrm{Ci} / \mathrm{g} \\
\text { Moisture }\left(10^{-6}\right) \\
\end{array}$ & $\begin{array}{r}\text { Maximum } \mu \mathrm{Ci} / \mathrm{g} \\
\text { Moisture }\left(10^{-6}\right) \\
\end{array}$ & $\begin{array}{ll}\text { Minimum } & \mu \mathrm{Ci} / \mathrm{g} \\
\text { Moisture } & \left(10^{-6}\right) \\
\end{array}$ \\
\hline VS-01 & 11 & 41.1 & $0.28 \pm 0.40$ & $1.40 \pm 0.40$ & $0.0 \pm 0.40$ \\
\hline VS- 02 & 11 & 42.3 & $0.22 \pm 0.35$ & $1.20 \pm 0.30$ & $0.0 \pm 0.40$ \\
\hline VS-03 & 11 & 34.4 & $0.25 \pm 0.36$ & $2.20 \pm 0.40$ & $0.0 \pm 0.40$ \\
\hline VS- 04 & 11 & 33.5 & $0.17 \pm 0.37$ & $1.90 \pm 0.40$ & $0.0 \pm 0.40$ \\
\hline VS-05 & 11 & 45.5 & $5.56 \pm 0.45$ & $60.80 \pm 0.90$ & $0.0 \pm 0.40$ \\
\hline VS-06 & 11 & 48.4 & $0.13 \pm 0.37$ & $1.40 \pm 0.40$ & $0.0 \pm 0.40$ \\
\hline VS- 07 & 11 & 33.9 & $0.28 \pm 0.40$ & $1.90 \pm 0.40$ & $0.0 \pm 0.40$ \\
\hline VS- 08 & 11 & 48.3 & $0.32 \pm 0.35$ & $1.80 \pm 0.40$ & $0.0 \pm 0.40$ \\
\hline VS-09 & 11 & 46.6 & $0.33 \pm 0.37$ & $2.40 \pm 0.40$ & $0.0 \pm 0.40$ \\
\hline IS-10 & 11 & 35.2 & $0.48 \pm 0.38$ & $2.80 \pm 0.40$ & $0.0 \pm 0.40$ \\
\hline VS-11 & 11 & 24.6 & $0.23 \pm 0.37$ & $1.90 \pm 0.40$ & $0.0 \pm 0.40$ \\
\hline$V S-12$ & 11 & 31.6 & $0.36 \pm 0.36$ & $2.20 \pm 0.40$ & $0.0 \pm 0.40$ \\
\hline VS-13 & 11 & 39.8 & $0.33 \pm 0.40$ & $1.90 \pm 0.40$ & $0.0 \pm 0.40$ \\
\hline VS-14 & 11 & 35.7 & $0.25 \pm 0.35$ & $1.90 \pm 0.40$ & $0.0 \pm 0.40$ \\
\hline VS-15 & 11 & 42.7 & $0.31 \pm 0.40$ & $2.10 \pm 0.40$ & $0.0 \pm 0.40$ \\
\hline VS-16 & 11 & 37.3 & $0.30 \pm 0.37$ & $1.90 \pm 0.40$ & $0.0 \pm 0.40$ \\
\hline
\end{tabular}

Minimum Detectable Limit $=4 \times 10^{-7} \mu \mathrm{Ci} / \mathrm{g}$ moisture Reported errors are at the $95 \%$ confidence level 
Table XXIII. Total Uranium in Jackrabbit for 1977

\section{Specimen \\ Identification}

Sewage Treatment

Plant

(A)

(B)

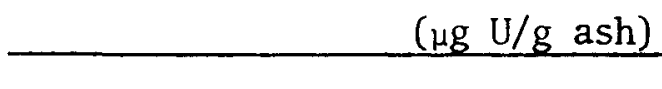

Lung

Kidney

Muscle

(Flesh) Bone

0.16

0.52

0.42

0.03

0.12

0.23

0.26

0.06

0.15

Retention

Playa

(A) 0.02

0.31

0.18

0.04

0.48

(B)

0.20

0.37

0.68

0.05

0.08

Zone 12
(A) 0.10
(B)
0.01

0.28

0.34

0.08

0.09

0.04

0.07

0.16

0.26

Firing Site
(A)
0.01
0.17
0.04
0.05
0.11
(B)
0.09
0.04
0.07
0.06
0.08

Radioactive Waste Storage Area (A)
0.33

0.26

0.58

0.15

0.13

(B)

0.05

0.07

0.79

0.10

0.07 
Table XXIV. Plutonium-239 in Jackrabbit for 1977

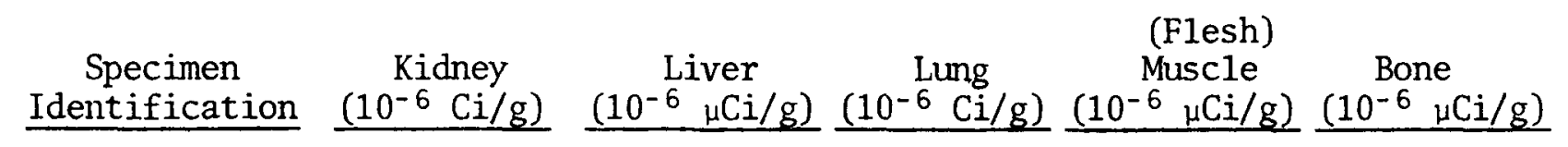

Sewage Treatment
Plant
(A) $0.00 \pm 0.15 \quad 0.00 \pm 0.02$
$0.00 \pm 0.13$
$0.00 \pm 0.02$
$0.00 \pm 0.01$
(B) $0.00 \pm 0.25 \quad 0.00 \pm 0.02$
$0.00 \pm 0.10$
$0.00 \pm 0.02$
$0.00 \pm 0.01$

Retention P1aya
(A) $0.00 \pm 0.13 \quad 0.00 \pm 0.04$
$0.00 \pm 0.10$
$0.00 \pm 0.02$
$0.00 \pm 0.01$
(B) $0.00 \pm 0.11 \quad 0.00 \pm 0.04$
$0.00 \pm 0.03$
$0.00 \pm 0.02$
$0.00 \pm 0.01$

Zone 12
(A) $0.00 \pm 0.30$
$0.00 \pm 0.01$
$0.00 \pm 0.21$
$0.00 \pm 0.02$
$0.00 \pm 0.01$
(B) $0.00 \pm 0.06 \quad 0.00 \pm 0.04$
$0.00 \pm 0.16$
$0.00 \pm 0.02$
$0.00 \pm 0.01$

Firing Site
(A) $0.00 \pm 0.07 \quad 0.00 \pm 0.02$
$0.00 \pm 0.06$
$0.00 \pm 0.02$
$0.00 \pm 0.01$
(B) $0.00 \pm 0.04 \quad 0.00 \pm 0.02$
$0.00 \pm 0.04$
$0.00 \pm 0.02$
$0.00 \pm 0.01$

Radioactive Waste

$\begin{array}{lllllll}\text { Storage Area }(A) & 0.00 \pm 0.05 & 0.00 \pm 0.01 & 0.00 \pm 0.04 & 0.00 \pm 0.02 & 0.00 \pm 0.01\end{array}$

(B) $\quad 0.00 \pm 0.09 \quad 0.00 \pm 0.02 \quad 0.00 \pm 0.02 \quad 0.00 \pm 0.02 \quad 0.00 \pm 0.01$

Minimum Detectable Limit $=2 \times 10^{-8} \mu \mathrm{Ci} / \mathrm{g} \mathrm{Ash}$

Errors when reported are counting errors at $95 \%$ confidence level 
Table XXV. Tritium in Jackrabbit for 1977

\begin{tabular}{|c|c|c|c|c|c|c|c|c|c|}
\hline \multicolumn{2}{|l|}{$\begin{array}{c}\text { Specimen } \\
\text { Identification } \\
\end{array}$} & $\begin{array}{r}\text { Kidney } \\
\text { (pCi/g } \\
\text { moisture) } \\
\end{array}$ & $\begin{array}{c}\text { Moisture } \\
\left(\begin{array}{l}0 \\
0\end{array}\right)\end{array}$ & $\begin{array}{c}\text { Liver } \\
\text { (pCi/g } \\
\text { moisture) } \\
\end{array}$ & $\begin{array}{c}\text { Moisture } \\
(\%) \\
\end{array}$ & $\begin{array}{c}\text { Lung } \\
\text { (pCi/g } \\
\text { moisture) }\end{array}$ & $\begin{array}{c}\text { Moisture } \\
\left(\begin{array}{l}0 \\
0\end{array}\right) \\
\end{array}$ & $\begin{array}{r}\text { (Flesh) } \\
\text { Muscle } \\
\text { (pCi/g } \\
\text { moisture) } \\
\end{array}$ & $\begin{array}{c}\text { Moisture } \\
(\%) \\
\end{array}$ \\
\hline \multicolumn{10}{|l|}{ Sewage Treatment } \\
\hline \multirow[t]{2}{*}{$\begin{array}{l}\text { Plant } \\
\text { Platis }\end{array}$} & (A) & $0.0 \pm 0.4$ & 75.0 & $0.0 \pm 0.4$ & 80.0 & $0.0 \pm 0.4$ & 77.0 & $0.0 \pm 0.4$ & 62.4 \\
\hline & (B) & $0.0 \pm 0.4$ & 71.4 & $0.0 \pm 0.4$ & 70.0 & $0.0 \pm 0.4$ & 79.0 & $0.0 \pm 0.4$ & 65.0 \\
\hline \multirow[t]{2}{*}{ Retention Basin } & (A) & $0.0 \pm 0.4$ & 72.0 & $0.0 \pm 0.4$ & 64.0 & $0.0 \pm 0.4$ & 74.0 & $0.0 \pm 0.4$ & 80.2 \\
\hline & (B) & $0.0 \pm 0.4$ & 85.0 & $0.0 \pm 0.4$ & 75.0 & $0.0 \pm 0.4$ & 79.0 & $0.0 \pm 0.4$ & 68.8 \\
\hline \multirow[t]{2}{*}{ Zone 12} & (A) & $0.0 \pm 0.4$ & 71.4 & $0.0 \pm 0.4$ & 72.0 & $0.0 \pm 0.4$ & 79.0 & $0.0 \pm 0.4$ & 78.5 \\
\hline & (B) & $0.0 \pm 0.4$ & 70.0 & $0.0 \pm 0.4$ & 72.0 & $0.0 \pm 0.4$ & 83.0 & $0.0 \pm 0.4$ & 80.0 \\
\hline \multirow[t]{2}{*}{ Firing Site } & (A) & $0.0 \pm 0.4$ & 70.0 & $0.0 \pm 0.4$ & 71.0 & $0.0 \pm 0.4$ & 81.0 & $0.0 \pm 0.4$ & 63.1 \\
\hline & (B) & $0.0 \pm 0.4$ & 48.0 & $0.0 \pm 0.4$ & 69.0 & $0.0 \pm 0.4$ & 75.0 & $0.8 \pm 0.4$ & 65.0 \\
\hline \multirow{2}{*}{\multicolumn{10}{|c|}{$\begin{array}{l}\text { Radioactive Waste } \\
\text { Storage Area (A) }\end{array}$}} \\
\hline & & & & & & & & & \\
\hline & (B) & $0.0 \pm 0.4$ & 74.7 & $0.0 \pm 0.4$ & 69.0 & $0.0 \pm 0.4$ & 70.0 & $0.0 \pm 0.4$ & 67.0 \\
\hline
\end{tabular}

Minimum Detectable Limit $=0.4 \mathrm{pCi} / \mathrm{g}$ moisture

Errors where reported are counting error at the $95 \%$ confidence level 
Table XXVI. Organ Weights of Jackrabbit for 1977

\begin{tabular}{llrrrr}
$\begin{array}{c}\text { Specimen } \\
\text { Identification }\end{array}$ & & $\begin{array}{c}\text { Kidney } \\
\text { (g) }\end{array}$ & \multicolumn{1}{c}{$\begin{array}{c}\text { Lung } \\
\text { (g) }\end{array}$} & $\begin{array}{c}\text { Liver } \\
\text { (g) }\end{array}$ \\
Sewage Treatment Plant & (A) & 11.6 & & 14.5 & 19.5 \\
& (B) & 7.0 & 30.6 & 53.0 \\
Retention P1aya & (A) & 13.5 & 16.9 & 33.1 \\
& (B) & 16.7 & 52.0 & 53.0 \\
Zone 12, 12-42 & (A) & 7.0 & 31.2 & 55.0 \\
& (B) & 20.0 & 16.2 & 20.2 \\
Firing Site & (A) & 13.2 & 44.8 & 71.1 \\
& (B) & 20.5 & 49.1 & 68.0 \\
Radioactive Waste & (A) & 21.0 & 55.0 & 65.1 \\
Storage Area & (B) & 17.0 & 12.0 & 68.1
\end{tabular}


Table XXVII. Sumnary of Chemical Analyses for Water Pollutants for 1977

\begin{tabular}{|c|c|c|c|c|c|c|c|}
\hline Analysis & $\begin{array}{c}\text { Sample } \\
\text { Identification } \\
\end{array}$ & $\begin{array}{l}\text { Number } \\
\text { Samples }\end{array}$ & Average & $\frac{\mathrm{mg} / \mathrm{l}}{\text { Maximum }}$ & Minimum & $\begin{array}{l}\text { Minimum } \\
\text { Criteria } \\
\text { (mg/l) } \\
\end{array}$ & $\begin{array}{c}\text { Detectable } \\
\text { Limit } \\
\text { (mg/l) }\end{array}$ \\
\hline $\mathrm{Ag}$ & $\begin{array}{l}\text { Pantex Lake (PL) } \\
\text { Retention Playa (RP) } \\
\text { Ground Water (GW) } \\
\text { Test Wells (TW) } \\
\text { Sewage Treatment } \\
\text { Discharge (STD) }\end{array}$ & $\begin{array}{l}2 \\
2 \\
5 \\
1 \\
1\end{array}$ & $\begin{array}{l}<0.01 \\
<0.01 \\
<0.01 \\
<0.01 \\
<0.01\end{array}$ & $\begin{array}{l}- \\
- \\
- \\
-\end{array}$ & $\begin{array}{l}- \\
- \\
- \\
- \\
-\end{array}$ & 0.05 & 0.01 \\
\hline As & $\begin{array}{l}\text { PL } \\
\text { RP } \\
\text { GW } \\
\text { TW } \\
\text { STD }\end{array}$ & $\begin{array}{l}3 \\
4 \\
6 \\
8 \\
3\end{array}$ & $\begin{array}{l}0.17 \\
0.01 \\
0.01 \\
0.02 \\
0.01\end{array}$ & $\begin{array}{l}0.03 \\
0.02 \\
0.02 \\
0.03 \\
0.02\end{array}$ & $\begin{array}{l}<0.01 \\
<0.01 \\
<0.01 \\
<0.01 \\
<0.01\end{array}$ & $\begin{array}{l}0.1 \\
0.05 \\
0.1\end{array}$ & 0.01 \\
\hline $\mathrm{Ba}$ & $\begin{array}{l}\text { PL } \\
\text { RP } \\
\text { GW } \\
\text { TW } \\
\text { STD }\end{array}$ & $\begin{array}{l}2 \\
2 \\
5 \\
1 \\
1\end{array}$ & $\begin{array}{l}0.4 \\
0.6 \\
0.3 \\
0.6 \\
0.5\end{array}$ & $\begin{array}{l}0.5 \\
0.6 \\
0.7 \\
- \\
-\end{array}$ & $\begin{array}{c}0.3 \\
0.5 \\
0.1 \\
- \\
-\end{array}$ & 1.0 & 0.1 \\
\hline $\mathrm{Cd}$ & $\begin{array}{l}\text { PL } \\
\text { RP } \\
\text { GW } \\
\text { TW } \\
\text { STD }\end{array}$ & $\begin{array}{l}3 \\
4 \\
6 \\
8 \\
3\end{array}$ & $\begin{aligned}< & 0.001 \\
& 0.0013 \\
< & 0.001 \\
< & 0.001 \\
< & 0.001\end{aligned}$ & $\begin{array}{l}- \\
0.002 \\
0.001 \\
0.003 \\
-\end{array}$ & $\begin{aligned} & - \\
< & 0.001 \\
< & 0.001 \\
< & 0.001\end{aligned}$ & $\begin{array}{l}0.005 \\
0.01 \\
0.005\end{array}$ & 0.001 \\
\hline $\operatorname{Cr}$ (Total) & $\begin{array}{l}\mathrm{PL} \\
\mathrm{RP} \\
\mathrm{GW} \\
\mathrm{TW} \\
\mathrm{STD}\end{array}$ & $\begin{array}{l}3 \\
4 \\
6 \\
8 \\
3\end{array}$ & $\begin{array}{l}0.002 \\
0.004 \\
0.004 \\
0.048 \\
0.003\end{array}$ & $\begin{array}{l}0.003 \\
0.007 \\
0.006 \\
0.115 \\
0.004\end{array}$ & $\begin{array}{r}0.001 \\
0.001 \\
0.002 \\
<0.001 \\
0.002\end{array}$ & $\begin{array}{l}5.0 \\
0.05 \\
5.0\end{array}$ & \\
\hline
\end{tabular}


Table XXVII. Cont'd

\begin{tabular}{|c|c|c|c|c|c|c|c|}
\hline Analysis & $\begin{array}{c}\text { Sample } \\
\text { Identification } \\
\end{array}$ & $\begin{array}{l}\text { Number } \\
\text { Samples }\end{array}$ & Average & $\frac{\mathrm{mg} / \mathrm{l}}{\text { Maximum }}$ & Minimum & $\begin{array}{l}\text { Minimum } \\
\text { Criteria } \\
(\mathrm{mg} / \mathrm{l})\end{array}$ & $\begin{array}{c}\text { Detectable } \\
\text { Limit } \\
(\mathrm{mg} / \mathrm{l}) \\
\end{array}$ \\
\hline $\mathrm{Cr}^{+6}$ & $\begin{array}{l}\text { PL } \\
\text { RP } \\
\text { GW } \\
\text { TW } \\
\text { STD }\end{array}$ & $\begin{array}{l}3 \\
4 \\
6 \\
8 \\
3\end{array}$ & $\begin{aligned}< & 0.01 \\
< & 0.01 \\
< & 0.01 \\
& 0.03 \\
< & 0.01\end{aligned}$ & $\begin{array}{l}- \\
- \\
- \\
0.12 \\
-\end{array}$ & $\begin{array}{c}- \\
- \\
- \\
<0.01 \\
-\end{array}$ & $\begin{array}{l}5.0 \\
0.05 \\
5.0\end{array}$ & 0.01 \\
\hline $\mathrm{Cu}$ & $\begin{array}{l}\text { PL } \\
\text { RP } \\
\text { GW } \\
\text { TW } \\
\text { STD }\end{array}$ & $\begin{array}{l}3 \\
4 \\
6 \\
8 \\
3\end{array}$ & $\begin{array}{l}0.008 \\
0.010 \\
0.003 \\
0.002 \\
0.011\end{array}$ & $\begin{array}{l}0.011 \\
0.013 \\
0.007 \\
0.003 \\
0.018\end{array}$ & $\begin{aligned} & 0.006 \\
& 0.005 \\
< & 0.001 \\
< & 0.001 \\
< & 0.001\end{aligned}$ & $\begin{array}{l}0.2 \\
0.2\end{array}$ & 0.001 \\
\hline Cyanide & $\begin{array}{l}\text { PL } \\
\text { RP } \\
\text { GW } \\
\text { TW } \\
\text { STD }\end{array}$ & $\begin{array}{l}3 \\
4 \\
6 \\
8 \\
3\end{array}$ & $\begin{array}{l}<0.1 \\
<0.1 \\
<0.1 \\
<0.1 \\
<0.1\end{array}$ & $\begin{array}{l}- \\
- \\
- \\
-\end{array}$ & $\begin{array}{l}- \\
- \\
- \\
-\end{array}$ & & 0.1 \\
\hline$F$ & $\begin{array}{l}\text { PL } \\
\text { RP } \\
\text { GW } \\
\text { TW } \\
\text { STD }\end{array}$ & $\begin{array}{l}2 \\
2 \\
5 \\
1 \\
1\end{array}$ & $\begin{array}{l}0.86 \\
1.03 \\
1.06 \\
1.92 \\
1.87\end{array}$ & $\begin{array}{l}1.36 \\
1.1 \\
1.87 \\
- \\
-\end{array}$ & $\begin{array}{l}0.36 \\
0.96 \\
0.17 \\
- \\
-\end{array}$ & 2.0 & 0.01 \\
\hline $\mathrm{Fe}$ & $\begin{array}{l}\text { PL } \\
\text { RP } \\
\text { GW } \\
\text { TW } \\
\text { STD }\end{array}$ & $\begin{array}{l}3 \\
4 \\
6 \\
8 \\
3\end{array}$ & $\begin{array}{l}0.57 \\
0.21 \\
0.08 \\
0.39 \\
0.12\end{array}$ & $\begin{array}{l}1.08 \\
0.68 \\
0.26 \\
1.38 \\
0.25\end{array}$ & $\begin{array}{l}0.03 \\
0.03 \\
0.02 \\
0.05 \\
0.04\end{array}$ & & 0.005 \\
\hline $\mathrm{Hg}$ & $\begin{array}{l}\text { PL } \\
\text { RP } \\
\text { GW } \\
\text { TW } \\
\text { STD }\end{array}$ & $\begin{array}{l}3 \\
4 \\
6 \\
8 \\
3\end{array}$ & $\begin{array}{l}0.0007 \\
0.0006 \\
0.0005 \\
0.0005 \\
0.0005\end{array}$ & $\begin{array}{l}0.0012 \\
0.0010 \\
0.0007 \\
0.0010 \\
0.0006\end{array}$ & $\begin{array}{l}<0.0004 \\
<0.0004 \\
<0.0004 \\
<0.0004 \\
<0.0004\end{array}$ & $\begin{array}{l}0.002 \\
0.002 \\
0.002\end{array}$ & 0.0004 \\
\hline
\end{tabular}


Table XXVII. Cont'd

\begin{tabular}{|c|c|c|c|c|c|c|c|}
\hline Analysis & $\begin{array}{c}\text { Sample } \\
\text { Identification }\end{array}$ & $\begin{array}{l}\text { Number } \\
\text { Samples }\end{array}$ & Average & $\frac{\mathrm{mg} / \mathrm{l}}{\text { Maximum }}$ & Minimum & $\begin{array}{l}\text { Minimum } \\
\text { Criteria } \\
\text { (mg/ /) }\end{array}$ & $\begin{array}{c}\text { Detectable } \\
\text { Limit } \\
\left(\mathrm{mg}^{\prime} \mathrm{l}\right) \\
\end{array}$ \\
\hline $\mathrm{NO}^{-3}$ & $\begin{array}{l}\text { PL } \\
\text { RP } \\
\text { GW } \\
\text { TW } \\
\text { STD }\end{array}$ & $\begin{array}{l}3 \\
4 \\
6 \\
8 \\
3\end{array}$ & $\begin{array}{l}2.3 \\
3.1 \\
2.2 \\
2.4 \\
3.6\end{array}$ & $\begin{array}{l}5.1 \\
4.5 \\
3.5 \\
5.1 \\
4.2\end{array}$ & $\begin{aligned}< & 0.1 \\
& 2.1 \\
& 1.0 \\
< & 0.1 \\
& 3.1\end{aligned}$ & 10.0 & 0.1 \\
\hline $\mathrm{Pb}$ & $\begin{array}{l}\text { PL } \\
\text { RP } \\
\text { GW } \\
\text { TW } \\
\text { STD }\end{array}$ & $\begin{array}{l}3 \\
4 \\
6 \\
8 \\
3\end{array}$ & $\begin{array}{l}<0.001 \\
<0.001 \\
<0.001 \\
<0.001 \\
<0.001\end{array}$ & $\begin{array}{l}- \\
- \\
- \\
-\end{array}$ & $\begin{array}{l}- \\
- \\
- \\
-\end{array}$ & $\begin{array}{l}5.0 \\
0.05 \\
5.0\end{array}$ & 0.001 \\
\hline Pheno1 & $\begin{array}{l}\text { PL } \\
\text { RP } \\
\text { GW } \\
\text { TW } \\
\text { STD }\end{array}$ & $\begin{array}{l}3 \\
4 \\
6 \\
8 \\
3\end{array}$ & $\begin{array}{l}<0.001 \\
<0.001 \\
<0.001 \\
<0.001 \\
<0.001\end{array}$ & $\begin{array}{l}- \\
- \\
- \\
-\end{array}$ & $\begin{array}{l}- \\
- \\
- \\
-\end{array}$ & & 0.001 \\
\hline $\mathrm{PO}_{4}$ & $\begin{array}{l}\text { PL } \\
\text { RP } \\
\text { GW } \\
\text { TW } \\
\text { STD }\end{array}$ & $\begin{array}{l}3 \\
4 \\
6 \\
8 \\
3\end{array}$ & $\begin{array}{l}1.0 \\
0.9 \\
0.3 \\
0.35 \\
0.9\end{array}$ & $\begin{array}{l}1.4 \\
1.1 \\
0.5 \\
0.9 \\
1.0\end{array}$ & $\begin{aligned} & 0.5 \\
& 0.7 \\
< & 0.1 \\
< & 0.1 \\
& 0.7\end{aligned}$ & & 0.1 \\
\hline $\mathrm{Se}$ & $\begin{array}{l}\text { PL } \\
\text { RP } \\
\text { GW } \\
\text { TW } \\
\text { STD }\end{array}$ & $\begin{array}{l}2 \\
2 \\
5 \\
1 \\
1\end{array}$ & $\begin{array}{l}<0.01 \\
<0.01 \\
<0.01 \\
<0.01 \\
<0.01\end{array}$ & $\begin{array}{l}- \\
- \\
- \\
-\end{array}$ & $\begin{array}{l}- \\
- \\
- \\
-\end{array}$ & 0.01 & 0.01 \\
\hline $\mathrm{SO}_{4}$ & $\begin{array}{l}\text { PL } \\
\text { RP } \\
\text { GW } \\
\text { TW } \\
\text { STD }\end{array}$ & $\begin{array}{l}3 \\
4 \\
6 \\
8 \\
3\end{array}$ & $\begin{array}{l}18.1 \\
57.9 \\
22.5 \\
33.7 \\
76.1\end{array}$ & $\begin{array}{r}25.1 \\
77.0 \\
26.7 \\
138.0 \\
130.0\end{array}$ & $\begin{array}{r}14.8 \\
18.1 \\
17.3 \\
4.0 \\
48.0\end{array}$ & $\begin{array}{r}50.0 \\
250.0\end{array}$ & 1.0 \\
\hline
\end{tabular}


Table XXVII. Cont'd

\begin{tabular}{|c|c|c|c|c|c|c|c|}
\hline Analysis & $\begin{array}{c}\text { Sample } \\
\text { Identification } \\
\end{array}$ & $\begin{array}{l}\text { Number } \\
\text { Samples }\end{array}$ & Average & $\frac{\mathrm{mg} / \mathrm{e}}{\text { Maximum }}$ & Minimum & $\begin{array}{l}\text { Minimum } \\
\text { Criteria } \\
(\mathrm{mg} / \mathrm{l}) \\
\end{array}$ & $\begin{array}{c}\text { Detectable } \\
\text { Limit } \\
(\mathrm{mg} / \mathrm{l}) \\
\end{array}$ \\
\hline $\begin{array}{l}\text { Total } \\
\text { Settleable } \\
\text { Solids }\end{array}$ & $\begin{array}{l}\text { PL } \\
\text { RP } \\
\text { GW } \\
\text { TW } \\
\text { STD }\end{array}$ & $\begin{array}{l}3 \\
4 \\
6 \\
8 \\
3\end{array}$ & $\begin{array}{r}0.7 \\
0.6 \\
<\quad 0.1 \\
15.8 \\
<\quad 0.1\end{array}$ & $\begin{array}{c}0.9 \\
1.2 \\
- \\
84.0 \\
-\end{array}$ & $\begin{array}{c}0.3 \\
<0.1 \\
- \\
1.5 \\
-\end{array}$ & & 0.1 \\
\hline $\begin{array}{l}\text { Total } \\
\text { Dissolved } \\
\text { Solids }\end{array}$ & $\begin{array}{l}\text { PL } \\
\text { RP } \\
\text { GW } \\
\text { TW } \\
\text { STD }\end{array}$ & $\begin{array}{l}3 \\
4 \\
5 \\
8 \\
3\end{array}$ & $\begin{array}{l}286.3 \\
446.7 \\
286.4 \\
273.0 \\
377.0\end{array}$ & $\begin{array}{l}309.0 \\
576.0 \\
325.0 \\
321.0 \\
457.0\end{array}$ & $\begin{array}{l}247.0 \\
155.0 \\
234.0 \\
246.0 \\
273.0\end{array}$ & & 1.0 \\
\hline $\mathrm{Zn}$ & $\begin{array}{l}\text { PL } \\
\text { RP } \\
\text { GW } \\
\text { TW } \\
\text { STD }\end{array}$ & $\begin{array}{l}3 \\
4 \\
6 \\
8 \\
3\end{array}$ & $\begin{array}{r}0.02 \\
0.01 \\
0.01 \\
<0.01 \\
0.02\end{array}$ & $\begin{array}{c}0.03 \\
0.02 \\
0.01 \\
- \\
0.03\end{array}$ & $\begin{array}{c}<0.01 \\
<0.01 \\
<0.01 \\
<0.01\end{array}$ & $\begin{array}{l}5.0 \\
5.0\end{array}$ & 0.01 \\
\hline $\begin{array}{l}\mathrm{pH} \text { (an arbritrary } \\
\text { unit, not } \mathrm{mg} / \mathrm{l} \text { ) }\end{array}$ & $\begin{array}{l}\text { PL } \\
\text { RP } \\
\text { GW } \\
\text { TW } \\
\text { STD }\end{array}$ & $\begin{array}{l}3 \\
4 \\
6 \\
8 \\
3\end{array}$ & $\begin{array}{l}7.54 \\
7.74 \\
8.09 \\
7.85 \\
8.04\end{array}$ & $\begin{array}{l}7.75 \\
8.15 \\
8.39 \\
8.50 \\
8.25\end{array}$ & $\begin{array}{l}7.36 \\
7.56 \\
7.57 \\
7.21 \\
7.92\end{array}$ & $>6.0 \&<9.0$ & 0.01 \\
\hline Oil/Grease & $\begin{array}{l}\text { PL } \\
\text { RP } \\
\text { GW } \\
\text { TW } \\
\text { STD }\end{array}$ & $\begin{array}{l}3 \\
4 \\
6 \\
8 \\
3\end{array}$ & $\begin{array}{l}2.4 \\
2.3 \\
7.1 \\
6.1 \\
6.6\end{array}$ & $\begin{array}{r}3.4 \\
4.1 \\
31.0 \\
13.6 \\
9.0\end{array}$ & $\begin{aligned}< & 1.0 \\
& 1.6 \\
< & 1.0 \\
< & 1.0 \\
& 5.2\end{aligned}$ & & 1.0 \\
\hline Hardness & $\begin{array}{l}\text { PL } \\
\text { RP } \\
\text { GW } \\
\text { TW } \\
\text { STD }\end{array}$ & $\begin{array}{l}3 \\
4 \\
6 \\
8 \\
3\end{array}$ & $\begin{array}{l}183.0 \\
205.5 \\
191.0 \\
191.0 \\
219.0\end{array}$ & $\begin{array}{l}211.0 \\
250.0 \\
202.0 \\
229.0 \\
244.0\end{array}$ & $\begin{array}{l}168.0 \\
137.0 \\
175.0 \\
148.0 \\
194.0\end{array}$ & & 1.0 \\
\hline
\end{tabular}


Table XXVII. Cont'd

\begin{tabular}{|c|c|c|c|c|c|c|c|}
\hline Analysis & $\begin{array}{c}\text { Sample } \\
\text { Identification } \\
\end{array}$ & $\begin{array}{l}\text { Number } \\
\text { Samples }\end{array}$ & Average & $\frac{\mathrm{mg} / \mathrm{l}}{\text { Maximum }}$ & Minimum & $\begin{array}{l}\text { Minimum } \\
\text { Criteria } \\
\text { (mg/l) } \\
\end{array}$ & $\begin{array}{l}\text { Detectable } \\
\text { Limit } \\
(\mathrm{mg} / \mathrm{l}) \\
\end{array}$ \\
\hline $\begin{array}{l}\mathbb{M x}^{a} \\
\text { (cyclotetrametylene } \\
\text { tetranitramine) }\end{array}$ & $\begin{array}{l}\text { PL } \\
\text { RP } \\
\text { GW } \\
\text { TW } \\
\text { STD }\end{array}$ & $\begin{array}{l}3 \\
4 \\
6 \\
8 \\
3\end{array}$ & $\begin{array}{l}<1 \mathrm{ppm} \\
<1 \mathrm{ppm} \\
<1 \mathrm{ppm} \\
<1 \mathrm{ppm} \\
<1 \mathrm{ppm}\end{array}$ & $\begin{array}{l}- \\
- \\
- \\
- \\
-\end{array}$ & $\begin{array}{l}- \\
- \\
- \\
-\end{array}$ & & $1 \mathrm{ppm}$ \\
\hline $\begin{array}{l}\mathrm{RDX}^{a} \\
\text { (hexahydro-1,3,5- } \\
\text { trinitro-sym-triazine) }\end{array}$ & $\begin{array}{l}\mathrm{PL} \\
\mathrm{RP} \\
\mathrm{GW} \\
\mathrm{TW} \\
\mathrm{STD}\end{array}$ & $\begin{array}{l}3 \\
4 \\
6 \\
8 \\
3\end{array}$ & $\begin{array}{l}<1 \mathrm{ppb} \\
<1 \mathrm{ppb} \\
<1 \mathrm{ppb} \\
<1 \mathrm{ppb} \\
<1 \mathrm{ppb}\end{array}$ & $\begin{array}{l}- \\
- \\
- \\
-\end{array}$ & $\begin{array}{l}- \\
- \\
- \\
-\end{array}$ & & $1 \mathrm{ppb}$ \\
\hline $\begin{array}{l}\text { PETN }^{a} \\
\text { (pentaerytritol- } \\
\text { tetranitrate) }\end{array}$ & $\begin{array}{l}\text { PL } \\
\text { RP } \\
\text { GW } \\
\text { TW } \\
\text { STD }\end{array}$ & $\begin{array}{l}3 \\
4 \\
6 \\
8 \\
3\end{array}$ & $\begin{array}{l}<5 \mathrm{ppb} \\
<5 \mathrm{ppb} \\
<5 \mathrm{ppb} \\
<5 \mathrm{ppb} \\
<5 \mathrm{ppb}\end{array}$ & $\begin{array}{l}- \\
- \\
- \\
-\end{array}$ & $\begin{array}{l}- \\
- \\
- \\
-\end{array}$ & & $5 \mathrm{ppb}$ \\
\hline Endrin & $\begin{array}{l}\mathrm{PL} \\
\mathrm{RP} \\
\mathrm{GW}\end{array}$ & $\begin{array}{l}3 \\
4 \\
6\end{array}$ & $\begin{array}{l}<0.0002 \\
<0.0002 \\
<0.0002\end{array}$ & $\begin{array}{l}- \\
-\end{array}$ & $\begin{array}{l}- \\
- \\
-\end{array}$ & 0.0002 & 0.0002 \\
\hline Lindane & $\begin{array}{l}\mathrm{PL} \\
\mathrm{RP} \\
\mathrm{GW}\end{array}$ & $\begin{array}{l}3 \\
4 \\
6\end{array}$ & $\begin{array}{l}<0.004 \\
<0.004 \\
<0.004\end{array}$ & $\begin{array}{l}- \\
-\end{array}$ & $\begin{array}{l}- \\
-\end{array}$ & 0.004 & 0.004 \\
\hline Methoxy Chlor & $\begin{array}{l}\mathrm{PL} \\
\mathrm{RP} \\
\mathrm{GW}\end{array}$ & $\begin{array}{l}3 \\
4 \\
6\end{array}$ & $\begin{array}{l}<0.1 \\
<0.1 \\
<0.1\end{array}$ & $\begin{array}{l}- \\
-\end{array}$ & $\begin{array}{l}- \\
- \\
-\end{array}$ & 0.1 & 0.1 \\
\hline Toxaphene & $\begin{array}{l}\text { PL } \\
\text { RP } \\
\text { GW }\end{array}$ & $\begin{array}{l}3 \\
4 \\
6\end{array}$ & $\begin{array}{l}<0.005 \\
<0.005 \\
<0.005\end{array}$ & $\begin{array}{l}- \\
-\end{array}$ & $\begin{array}{l}- \\
- \\
-\end{array}$ & & 0.005 \\
\hline
\end{tabular}

$a_{H i g h}$ Explosive Compound 
Table XXVII. Cont'd

\begin{tabular}{|c|c|c|c|c|c|c|c|}
\hline Analysis & $\begin{array}{c}\text { Sample } \\
\text { Identification } \\
\end{array}$ & $\begin{array}{l}\text { Number } \\
\text { Samples }\end{array}$ & Average & $\frac{\mathrm{mg} / \mathrm{e}}{\text { Maximum }}$ & Minimum & $\begin{array}{l}\text { Minimum } \\
\text { Criteria } \\
(\mathrm{mg} / \mathrm{l}) \\
\end{array}$ & $\begin{array}{c}\text { Detectable } \\
\text { Limit } \\
(\mathrm{mg} / \mathrm{l}) \\
\end{array}$ \\
\hline $2,4-D$ & $\begin{array}{l}\text { PL } \\
\text { RP } \\
\text { GW }\end{array}$ & $\begin{array}{l}3 \\
4 \\
6\end{array}$ & $\begin{array}{l}<0.1 \\
<0.1 \\
<0.1\end{array}$ & - & - & 0.1 & 0.1 \\
\hline $\begin{array}{l}2,4,5-\mathrm{TP} \\
\text { (Silvex) }\end{array}$ & $\begin{array}{l}\mathrm{PL} \\
\mathrm{RP} \\
\mathrm{GW}\end{array}$ & $\begin{array}{l}3 \\
4 \\
6\end{array}$ & $\begin{array}{l}<0.01 \\
<0.01 \\
<0.01\end{array}$ & $\begin{array}{l}- \\
-\end{array}$ & - & 0.01 & 0.01 \\
\hline Suspended Solids & STD & 36 & 0.94 & 3.68 & 0.0 & 30.0 & 1.0 \\
\hline BOD & $\begin{array}{l}\mathrm{RP} \\
\mathrm{STD}\end{array}$ & $\begin{array}{l}41 \\
37\end{array}$ & $\begin{array}{r}46.16 \\
3.73\end{array}$ & $\begin{array}{r}758.25 \\
17.76\end{array}$ & $\begin{array}{l}1.44 \\
0.0\end{array}$ & 30.0 & 0.1 \\
\hline $\begin{array}{l}\text { Fecal Coliform } \\
\text { (measured in } \\
\text { counts } / 100 \mathrm{ml} \text { ) }\end{array}$ & $\begin{array}{l}\text { RP } \\
\text { GW } \\
\text { STD }\end{array}$ & $\begin{array}{r}38 \\
100 \\
36\end{array}$ & $\begin{array}{r}671.4 \\
0.0 \\
6863.9 \quad 3\end{array}$ & $\begin{array}{c}9800.0 \\
- \\
350,000.00\end{array}$ & $\begin{array}{l}0.0 \\
- \\
0.0\end{array}$ & 200.0 & 1.0 \\
\hline
\end{tabular}




\section{REFERENCES}

1. Thom, H. C. G., "Tornado Probabilities," Monthly Weather Review, Vo1. 91 (October - December 1962).

2. Uniform Building Code, 1970.

3. Percolation of Water Through Pullman Soils, Texas High Plains, The Texas Agricultural Experimental Station, 1971.

4. Basin Recharge of the Ogallala Aquifer, Southwestern Great Plains Research Center, 1972.

5. Hydrogeology of a Playa Near Amarillo, Texas, Southwestern Great Plains Research Center, 1971.

6. Texas Almanac and State Industria1 Guide 1976-1977, The Da1las Morning News, AH Belo Corporation, 1975.

7. Users Guide for the Climatalogical Dispersion Model by Adrian D. Busse and John R. Zimmerman, EPA-R4-73-024, December 1973.

8. Local Climatological Data, U. S. Department of Commerce, National Oceanic and Atmospheric Administration, January 1976 through December 1976.

9. Martin, J. A., Jr., "Calculations of Environmental Radiation Exposures and Population Doses Due to Effluents from a Nuclear Fuel Reprocessing Plant," Radiation Data and Reports, Vo1. 15, No. 2 February 1973.

10. DOE Manual Chapter 0524, Standards for Radiation Protection.

11. National Interim Primary Drinking Water Regulations, Title 40, Part 141, Environmental Protection Agency, December 24, 1975.

12. Water Quality Criteria, Federal Water Pollution Control Agency, U.S. Department of Interior, Washington, D.C., 1968.

13. 40 CFR 133, Title 40, Protection of Environment, Environmental Protection Agency, Part 133 - Secondary Treatment Information, October 10, 1973.

14. Standard Methods for the Examination of Water and Waste Water, Thirteenth Edition, American Public Health Association, New York, NY 1971.

15. James J. Mueller, Controls for Environmental Pollution Inc., Santa Fe, NM, Private correspondence, December 8, 1975.

16. Methods for Chemical Analyses of Water and Wastes, Environmental Protection Agency, Water Quality office, Analytical Control Laboratory, Cincinnati, Ohio, 1971, 16020, 07/71. 


\section{STANDARDS FOR RADIOACTIVITY IN AIR AND WATER}

Generally standards for radioactivity in air and water are derived from DOE Manua1 Chapter 0524 and its appendix(10). The Radioactivity Concentration Guides (RCG's) for uncontrolled areas are generally the concentrations at which an individual if continually exposed would receive about 0.500 rem total body dose equivalent per year. RCG's for the general population are approximately $1 / 3$ of the RCG's for uncontrolled areas so that the general population will receive no more than 0.170 rem total dose equivalent per year or not more than 0.500 rem to the lungs or kidney when these serve as the critical organ.
In the case of mixtures of specific nuclides, the resultant RCG is determined such that the sum of the ratios of the concentrations of each nuclide to its respective RCG does not exceed unity. Nuclide concentrations are not considered part of a mixture whenever the concentration to RCG ratio is less than or equal to 0.1 and the sum of the ratios for all nuclides is less than 0.25 .

RCG's for gross activity in air and water were not referenced for 1977 data due to complications introduced by fallout from recent weapons tests and pending EPA regulations concerning primary drinking water standards.

\section{RADIOACTIVITY CONCENTRATION GUIDES FOR SOIL AND VEGETATION}

Presently there are no published generally accepted RCG's for radio- nuclides in soil and vegetation.

\section{NON-RADIOACTIVE WATER QUALITY STANDARDS}

Non-radioactive analyses are compared to applicable EPA Primary Drinking Water Standards 40 CFR 141, Recommendations of the U. S. Federal Water
Pollution Control Administration and EPA Secondary Treatment Regulations 40 CFR $133(11,12,13)$.

\section{STATISTICAL METHODS}

Non-radioactive measurements are based on analog representations of physical parameters and a lower limit exists as to the sensitivity of the techniques and instrumentation employed. When measurements of non-radioactive parameters were performed and no indication in excess of lower detection limit was observed, the result is presented as less than (<) the minimm detectable limit. Average values were calculated by assuming the minimum detectable limit where positive indications were not obtained and portrayal of the final average as a less than value. The less than value for an average therefore indicates the assumption of the minimum detectable limit for one or more terms within the average. 
Radioactive measurements however are subject to the statistical nature of radioactive decay and are presented in conjunction with an associated statistical error. All errors presented represent counting error only, no attempt has been made to quantify systematic errors. The minimum detectable limit of a radioactive parameter has been conservatively expressed as the standard deviation of the measurement at the point for which the technique is no longer sensitive at the desired confidence level. This treatment is further conservative in that statistically significantly negative numbers are assumed to be zero. Negative numbers can arise from statistical fluctuations in the radioactive decay of the sample, the blank, or in the background of the counting device. Averages are taken using zero for values which are less than the minimum detectable limit and by determining the associated error.

\section{ANALYTICAL METHODS - RADIOACTIVE}

AIR

\section{Air Filters}

Gross Alpha, Gross Beta

Filter paper samples are counted for gross alpha radioactivity on a low background internal flow proportional counter which simultaneously counts alpha and beta activity. Appropriate corrections are applied for absorption and counter efficiency.

\section{Total Uranium}

The sample is dissolved in $8 \mathrm{~N}$ $\mathrm{HNO}_{3}$, taken to dryness, and oxidized to remove organics. Then the sample is dissolved in $2 \mathrm{~N} \mathrm{Al}\left(\mathrm{NO}_{3}\right)_{3}$ and extracted into diethyl ether. The ether is dried and the sample transferred to a stainless steel planchet for counting in a proportional counter.

\section{Plutonium-239}

A Pu-236 tracer is added to the filter paper sample, totally dissolved and converted to the nitrate by additions of $\mathrm{HNO}_{3}$. The plutonium is separated using an ion exchange resin, eluted off the column, and electroplated on a stainless steel disc. A solid state Alpha Spectrometer is utilized to count the disc, and chemical recovery is determined from the tracer peak.

\section{Silica Ge1}

Moisture is removed from the silica gel using a distillation apparatus. A portion of the distillate is mixed with a scintillation solution and counted in a liquid scintillation spectrometer. The atmospheric tritium concentration is related to the tritium concentration of the distillate through the average absolute humidity for the month during which the sample was collected.

\section{Water}

Gross Alpha (Dissolved Solids)

After thorough agitation a suitable aliquot is taken for analysis. The aliquot is acidified and evaporated to dryness on a hot plate after which the residue is dissolved in $0.5 \mathrm{~N}$ $\mathrm{NHNO}_{3}$ and transferred to a tared planchet. Gross alpha radioactivi 
is then determined by counting the planchet in an internal flow proportional counter (Wide Beta II instrument).

The result is corrected for counter efficiency and selfabsorption if an appreciable solid residue is obtained. For thickness greater than $1 \mathrm{mg} / \mathrm{cm}^{2}$, a correction must be applied.

Gross Beta (Dissolved Solids)

This same method is used as described under Gross Alpha (Dissolved Solids). A selfabsorption correction factor is applied when the sample weight exceeds $1 \mathrm{mg} / \mathrm{cm}^{2}$.

Gross Alpha (Suspended Solids)

One litre of water is filtered through a millipore filter $(0.45$ $\mu \mathrm{m})$, the filter is counted utilizing a Wide Beta II Instrument.

Gross Beta (Suspended Solids)

The same method is used as described under Gross Alpha (Suspended Solids).

Tota1 Uranium

After evaporation of a suitable aliquot the sample is dissolved in $8 \mathrm{~N} \mathrm{HNO}_{3}$, taken to dryness and oxidized to remove organics. Then the sample is dissolved in $2 \mathrm{~N} \mathrm{Al}\left(\mathrm{NO}_{3}\right)_{3}$ and extracted into diethyl ether. The ether is dried and the sample transferred to a stainless steel planchet for counting in a proportional counter. plutonium-239

The total water sample is acidified and aliquoted. A Pu-236 tracer is added to the aliquot and the plutonium is precipitated as an alkaline-earth phosphate. The precipitate is separated, ashed, and dissolved in nitric acid. Plutonium is separated using an ion exchange resin, eluted off the colum, and electroplated on a stainless steel disc. A solid state Alpha Spectrometer is utilized to count the disc and chemical recovery is determined from the tracer peak.

\section{Tritium}

The water sample is distilled to remove quenching materials and nonvolatile radioactive materials. Distillation is carried to dryness to ensure complete transfer of the tritium to the distillate. A portion of the distillate is mixed with scintillation solution and counted in a liquid scintillation spectrometer. Standard tritium and background samples are prepared and counted alternately to nullify errors produced by aging of the scintillation medium or instrument drift. Each sample is counted for 500 minutes.

Soil

Tota1 Uranium

The sample is dissolved in $8 \mathrm{~N}$ $\mathrm{HNO}_{3}$, taken to dryness and oxidized to remove organics. Then the sample is dissolved in $2 \mathrm{~N} \mathrm{~A} 1\left(\mathrm{NO}_{3}\right)_{3}$ and extracted into diethyl ether. The ether is dried and the sample 
transferred to a stainless steel planchet for counting in a proportional counter.

\section{Plutonium}

The soil sample is totally dissolved using a $40 \%$ solution of $\mathrm{HF}$ and a Pu-236 tracer is added before dissolution. After fuming with $\mathrm{HF}$ the sample is converted to sulfate and brought up with $\mathrm{HNO}_{3}$. An ion exchange column is utilized to separate the plutonium which is subsequently eluted off the column and electroplated on a stainless steel counting disc. This disc is counted on a solid state alpha spectrometer and recovery is determined from the tracer peak.

\section{Tritium}

The water is extracted from the soil sample by azeotropic distillation with benzene. The distillation is carried to dryness to ensure complete transfer of the tritium. A portion of the distillate is mixed with scintil- lation solution and counted utilizing a liquid scintillation spectrometer. Standard tritium and background samples are prepared and coumted alternately to nullify errors produced by aging of the scintillation medium or instrument drift. Each sample will be counted for 500 minutes.

\section{Vegetation}

\section{Total Uranium}

After ashing the sample is dissolved in $8 \mathrm{NHNO}_{3}$, taken to dryness and oxidized to remove organics. Then the sample is dissolved in $2 \mathrm{~N} \mathrm{Al}\left(\mathrm{NO}_{3}\right)_{3}$ and extracted into diethyl ether. The ether is dried and the sample transferred to a stainless stee 1 planchet for counting in a proportional counter.

\section{Tritium}

The same method is used as described under Soil for Tritium analysis.

\section{ANALYTICAL METHODS - NON-RADIOACTIVE}

Water Quality

In genera1, non-radioactive analyses are performed in accordance with standard methods(14). Analysis for explosives and pesticides is accom- plished using an electron captur vapor phase chromatography technique (15). Mercury analyses are performed in accordance with an Environmental Protection Agency Standard Method(16). 


\section{QUALITY CONTROL}

Except for the gross alpha and gross beta in air and BOD analyses, all analyses during 1977 were performed under contract by Controls for Environmental Pollution (CEP) Inc. of Santa $\mathrm{Fe}$, New Mexico. The management of CEP administers the following three-phase quality control programs(15).

1. Al1 reagents, including carriers and tracer radionuclides, which are critical to the procedures in question are standardized and checked periodically by two different chemists. When possible the reagents are standardized using two different chemical procedures, e.g., strontium carrier-gravimetrically and atomic absorption.

2. A11 personne1 within the 1aboratory are required to run spiked samples to prove their proficiency in determining accurately the content of the spiked sample in question. Furthermore, to eliminate the possibility of preferential treatment of a spiked sample by an analyst, spiked samples are slipped into routinely analyzed samples without the knowledge of the analyst. Also, every set of samples has a spike and a blank rum concurrent1y with it.
3. All instrumentation is maintained on monthly preventive maintenance programs by the manufacturer. Each instrument is calibrated weekly. If the calibration detects any anomaly from the routine performance of the instrument, no analysis is allowed to be performed by that instrument until it is functioning properly. All radioactive sources and solutions used for calibration are calibrated against National Bureau of Standards' standards where possible. Interlaboratory comparisons with the U. S. Public Health Service, Environmental Protection Agency, United States Department of Energy, Department of the Navy, and the American Industrial $\mathrm{Hy}-$ giene Association.

4. CEP also participates in the Environmental Protection Agency's quality assurance tests.

5. CEP works in conjunction with Pantex Plant in the USDOE's environmental intercomparison measurement study.

6. It is also noted that CEP is certified by the American Industrial Hygiene Association. 


\section{RAOIOACTIVITY CONCENTRATION GUIDES (RCG'S)}

\begin{tabular}{|c|c|c|}
\hline \multicolumn{3}{|c|}{ Uncontrolled Area } \\
\hline & $\begin{array}{c}\operatorname{Air} \\
(\mu \mathrm{Ci} / \mathrm{m} \ell) \\
\end{array}$ & $\begin{array}{l}\text { Water } \\
(\mu \mathrm{Ci} / \mathrm{m} \ell)\end{array}$ \\
\hline Total Plutonium & $6 \times 10^{-14}$ & $5 \times 10^{-6}$ \\
\hline Tritium & $2 \times 10^{-7}$ & $3 \times 10^{-3}$ \\
\hline Uranium & $3 \times 10^{-12}$ & $4 \times 10^{-5}$ \\
\hline \multicolumn{3}{|c|}{ General Population } \\
\hline Total Plutonium & $2 \times 10^{-14}$ & $2 \times 10^{-6}$ \\
\hline Tritium & $1 \times 10^{-7}$ & $1 \times 10^{-3}$ \\
\hline Uranium & $1 \times 10^{-12}$ & $1 \times 10^{-5}$ \\
\hline
\end{tabular}

PERMISSIBLE ANNUAL POPULATION DOSES FOR KIDNEY ANO WHOLE BODY EXPOSURES

Reference Point

Site boundary and highest exposed individual or group

General Population
Kidney

(rem)

1.50

0.500

0.500
Total Body (rem)
Water

$5 \times 10^{-6}$

$3 \times 10^{-3}$

$4 \times 10^{-5}$

$1 \times 10^{-5}$ 


\section{WATER QUALITY CRITERIA}

\begin{tabular}{|c|c|c|c|}
\hline & $\begin{array}{l}\text { EPA } \\
\text { Drinking } \\
\text { Water } \\
\text { Regulations } \\
\text { (mg/l) } \\
\end{array}$ & $\begin{array}{c}\text { Federal Water Pollution } \\
\text { Control Administration } \\
\text { Criteria for } \\
\text { Trace Element Tolerances } \\
\text { for Irrigation Waters } \\
(\mathrm{mg} / \mathrm{l}) \\
\end{array}$ & $\begin{array}{l}\text { EPA } \\
\text { Secondary } \\
\text { Treatment } \\
\text { Regulations } \\
\text { (mg/l) } \\
\end{array}$ \\
\hline Arsenic (As) & 0.05 & 0.01 & 0.01 \\
\hline Barium (Ba) & 1.0 & 0.5 & 1.0 \\
\hline Cadmium (Cd) & 0.010 & 0.01 & 0.01 \\
\hline Chromium (Tota1) & 0.05 & - & 0.01 \\
\hline Chromium $(+6)$ & - & 0.02 & 0.05 \\
\hline Copper & - & 0.01 & 1.0 \\
\hline Cyanide & - & 0.20 & 0.2 \\
\hline Fluoride & $2.0 *$ & - & - \\
\hline Iron & - & 0.05 & 0.3 \\
\hline Lead & 0.05 & 0.01 & 0.05 \\
\hline Mercury & 0.002 & 0.002 & - \\
\hline Nitrate & 10 & 0.1 & 10 \\
\hline Phenol & - & - & 0.001 \\
\hline Thosphate & - & 0.1 & - \\
\hline Silver & 0.05 & 0.05 & - \\
\hline Sulfate & - & 50 & 250 \\
\hline Selenium & 0.01 & 0.01 & 0.01 \\
\hline Total Dissolved Solids & - & - & 500 \\
\hline Suspended Solids & - & 0.05 & 0.5 \\
\hline Zinc & - & 5.0 & - \\
\hline BOD ( 5 day) & - & - & 30.0 \\
\hline Fecal Coliform & $1 \mathrm{ct} / 100 \mathrm{~m} \mathrm{l}$ & - & $200.0 \mathrm{ct} / 100 \mathrm{ml}$ \\
\hline $\mathrm{pH}$ & - & - & $>6.0 \&<9.0$ \\
\hline \multicolumn{4}{|l|}{ Pesticides: } \\
\hline Aldrin & - & - & - \\
\hline Chlorodane & - & - & - \\
\hline DDT & - & - & - \\
\hline Dieldrin & - & - & - \\
\hline Endrin & 0.0002 & - & - \\
\hline Heptachlor & - & - & - \\
\hline Heptachlor Epoxide & - & - & - \\
\hline Lindane & 0.004 & - & - \\
\hline Methoxychlor & 0.1 & - & - \\
\hline Toxaphene & 0.005 & - & - \\
\hline $2,4-D$ & 0.1 & - & - \\
\hline $2,4,5-\mathrm{TP}$ (Silvex) & 0.01 & - & - \\
\hline
\end{tabular}

* This value for fluoride is based on an annual average maximum daily air temperature of $14.9 \mathrm{C}$. 
PERFORMANCE STANDARDS FOR STATIONARY SOURCES

Reference

Fossil Fueled Steam Generator
42 FR 37936 July 25, 1977 $\underline{\text { Standards }}$

Particulate: $0.10 \mathrm{1b} / 10^{6} \mathrm{BTU}$ Opacity: $\quad 20 \%$

$\begin{aligned} \mathrm{SO}_{2}: & 0.80 \mathrm{1b} / 10^{6} \mathrm{BTU} \\ & (1 \text { iquid fue1) } \\ & 1.21 \mathrm{~b} / 10^{6} \mathrm{BTU} \\ & (\text { solid fuel) } \\ \mathrm{NO}_{2}: \quad & 0.201 \mathrm{~b} / 10^{6} \mathrm{BTU} \\ & (\text { gas fue1) } \\ & 0.301 \mathrm{~b} / 10^{6} \mathrm{BTU} \\ & (1 \text { iquid fue1) } \\ & 0.701 \mathrm{~b} / 10^{6} \mathrm{BTU} \\ & \text { (solid fue1) }\end{aligned}$




\section{DISTRIBUTION}

No of Copies

DOE Albuquerque Operations Office/J. R. Roeder

DOE Amari11o Area Office/P. R. Wagner

DOE Technical Information Center

40

Amari11o Bi-City County Health Department

Environmental Protection Agency, Region VI

1

Lawrence Livermore Laboratory/H. W. Patterson

1

Los Alamos Scientific Laboratory/H. S. Jordan

1

Sandia Laboratories - Albuquerque/W. D. Barnett

1

Texas Air Control Board

1

Texas Water Quality Board, District No. 1

1

Southwestern Public Service Co./K. L. Ladd 